University of Zurich

Department of Economics

Working Paper Series

ISSN 1664-7041 (print)

ISSN 1664-705X (online)

Working Paper No. 150

\title{
Optimal Contracting with Endogenous Project Mission
}

\author{
Lea Cassar
}

Revised version, October 2014 


\title{
Optimal Contracting with Endogenous Project Mission
}

\author{
Lea Cassar*
}

October 28, 2014

\begin{abstract}
Empirical evidence shows that workers care about the mission of their job in addition to their wage. This suggests that employers can use the job mission to incentivize and screen their workers. I study a model in which a principal selects an agent to develop a project and influences the agent's ex post level of effort not by outcome-contingent rewards, but by the choice of the project mission. The principal's and the agents' preferences about the mission are misaligned and the degree to which an agent cares about the mission is private information. I derive the optimal mechanism (allocation rule, project mission, payment) to select and motivate the agent. I show that under the optimal mechanism the project mission is distorted towards the principal's ideal mission compared to the full information optimum. As a consequence, effort is lower. If the mission must be chosen prior to the allocation of the project, competition brings the principal to align the mission more with the agent's preferences, which increases his effort. Finally, in the presence of budget constraints, the principal should offer the same mission and the same payment to all types of agents. Several applications and links to the empirical evidence are discussed.
\end{abstract}

JEL Classification Codes: H41, D23, D82, M52

Keywords: optimal contracting, non-monetary incentives, mission preferences, intrinsic motivation

\footnotetext{
*University of Zürich, Blümlisalpstrasse 10, CH-8006, Zürich, Switzerland. Email: lea.cassar@econ.uzh.ch. I am particularly grateful to Konrad Mierendorff for his excellent supervision at different stages of the development of the project. I also would like to thank Gani Aldashev, Charles Angelucci, Mark Armstrong, Bjoern Bartling, Roland Benabou, Jean-Michel Benkert, Florian Ederer, Florian Engl, Florian Englmaier, Matthias Fahn, Sebastian Findeisen, Maitreesh Ghatak, Holger Herz, Lea Heursen, Jacob Goeree, Alexey Kushnir, Igor Letina, Ester Manna, Nick Netzer, Andrew Newman, Georg Nöldeke, Michael Powell, Maria Saez, Sarah Sandford, Klaus Schmidt, Ferdinand von Siemens, Marta Troya-Martinez, John Vickers, Roberto Weber, participants at the Workshop on Public Organizations, LSE N.G.O. workshop, Zurich Workshop of Economics, and European Public Choice Conference, for useful comments and suggestions. This paper has won the best paper award on "Public Organizations" sponsored by Unicredit \& Universities Foundation and replaces a previous version distributed under the title "Auctioning Incentive Contracts with Motivated Agents."
} 


\section{Introduction}

Empirical studies show that workers, especially those in the public and social sector, are often driven only partly by financial rewards, but also by the mission of their job, i.e., by the overall job design and characteristics: the type of good that is provided, how it is provided, to whom it is provided, and so on $L^{1}$ This evidence suggests that the job mission can be used as a contracting tool by governments and employers of international, public or social organizations, to incentivize and screen their workers. To date, however, we know little about the role of the mission in optimal contracting for the provision of public goods and services.

In this paper, I analyze a mechanism design problem in which a principal must select one among many agents to develop a project and can influence the level of effort that the selected agent will put into the project not by outcome-contingent rewards, but by the choice of the project mission. The principal and the agents derive an intrinsic benefit from pursuing certain (observable) missions and therefore, from the project being designed in a certain way. The closer is the project mission to an agent's ideal mission, the higher is the level of effort that the agent will put into the project. The mission preferences of the principal and of the agents are, however, misaligned. This misalignment implies that in choosing a project mission the principal faces a trade-off between pursuing his ideal mission and extracting effort from the selected agent. The agent's effort is, indeed, observable ex-post but not contractible. Furthermore, the degree to which the agent cares about the mission is his private information, i.e., the agents have heterogeneous and unobservable intrinsic motivation levels. Thus, the principal faces, in addition, an adverse selection problem.2

I derive the optimal rule that should be adopted by the principal to select the agent and the optimal contract, consisting of a project mission and a payment, that should be offered to that agent. I also consider a simpler mechanism in which the project mission is fixed prior to the allocation of the project and, therefore, in which the principal only uses the payment to screen the agents. Finally, I study the same optimal contracting problem, but in the presence of budget constraints. In this setting, the agent's effort can be interpreted as the agent's ex-post financial investment into the project, whose costs must be covered by the principal's payment, i.e., the budget. This extension captures the contracting of public projects that are highly

\footnotetext{
${ }^{1}$ Recent evidence includes Ashraf et al. (2014), Carpenter and Gong (2013), Gerhards (2013), Cassar (2014). See Perry et al. (2010) for a comprehensive overview of the empirical literature on public sector motivation in the last 20 years and Francois and Vlassopoulos (2008) for a review of the theoretical literature on this topic.

${ }^{2}$ Importantly, the ideal missions of the agents are assumed to be equally distant from the principal's ideal mission. This means that the screening problem faced by the principal is uni-dimensional and refers to the agents' intrinsic motivation. Mechanism design problems where private information is multi-dimensional are hardly tractable and highly dependent on the exact parameters' values and functions' specifications (Asker and Cantillon (2010).
} 
capital intensive, and where the agent has the expertise to make the investment but is not expected to financially contribute to the project. This is the case, for instance, in scientific and medical research projects or when the agent is an NGO with no access to independent resources. This extension, in addition to represent a novel theoretical problem, is of high relevance for the contracting over missions, because as it will be shown, the screening role of the mission is strongly tied to the principal's possibility of saving on the financial payments due to the agents with higher intrinsic motivation levels. When this possibility comes short, the mission fills solely an incentivizing role.

The analysis presented in this paper is relevant for a wide set of labor market environments where the mission of the job is part of the compensation package that a principal can use to select and motivate his employees. The model applies, for instance, to the design and allocation of procurement contracts for the provision of social goods and services. Governments and aid agencies regularly face the problem of selecting private organizations for the development of social projects in various fields (poverty reduction, education, health ...). Given that the contracts for the provision of public goods are often incomplete, the procurers must rely, to a large extent, on the unobservable intrinsic motivation of the selected organization's employees to put effort into the project. Furthermore, the procurer and the selected organization may not have identical preferences on how the project should be designed. Taking the example of an educational project, the government and the founders of a non-profit organization may have different views on the role of education and teaching methods: they may disagree on the educational curricula that should be taught, on how to select and pay the teachers, on whether to prioritize the quality versus the costs of education, on beneficiaries' targeting, on the role of religion in the school, and so on. Such "ideological" issues are frequently encountered in situations where non-profits are involved (Besley and Ghatak, 1999, 2001).

Similarly, the model can be applied to the design and allocation of research grants. Donors, such as public agencies or private foundations, must choose the allocation rule, the amount of the grant, and how many conditions to attach to the grant. These conditions typically concern the research questions that can be addressed, the research methods that can be used, and so on. The number of conditions and their level of detail will determine how much freedom the researcher will have to pursue his own research agenda, and in turn how much effort he will be willing to put into the project ${ }^{3}$ Thus, if donors have different, more policy oriented, research agendas than academics, they face similar trade-offs than the ones described in this paper.

More generally, this analysis applies to the optimal design of jobs within organizations

\footnotetext{
${ }^{3}$ It is worth emphasizing that the model is not meant to formalize the allocation of grants as a form of prizes for the best project's proposal, as it is the case in Che and Gale (2003). In my framework, there are no sunk investments. The effort decision is only made by the winning agent after he has been allocated the project.
} 
where employees care about the level of discretion they are given in solving their tasks.4 $4^{4}$ this respect, the paper points to a different "hidden cost of control" which, contrary to Falk and Kosfeld (2006), Bartling et al. (2012, 2013), does not arise from the perception that the lack of discretion is a signal of the principal's distrust, but from the fact that workers have direct preferences on how to solve their tasks, and these preferences are not always aligned with the ones of their employers. In this setting it may be optimal for the principal to offer his employee a menu of contracts with different levels of wage and discretion and let the employee self-select in one of these contracts based on his intrinsic motivation level. This paper looks at the optimal menu of contracts to offer to the employee.

This paper belongs to the contract theory literature with motivated agents (Besley and Ghatak, 2005; Chau and Huysentruyt, 2006; Delfgaauw and Dur, 2007, 2008; Murdock, 2002; Benabou and Tirole, 2003, 2006). In an important part of the literature, the worker's intrinsic benefit of exerting effort has been assumed to depend on the (exogenous) intrinsic motivation level of the agent only. This intrinsic motivation varies across agents and is unobservable to the principal, leading to an optimal contracting problem with adverse selection 5 These papers, however, do not model mission preferences. Therefore, the principal has no power of influencing the intrinsic motivation of the agents.

In the seminal paper by Besley and Ghatak (2005), principal and agents are assumed to derive an intrinsic benefit from pursuing certain missions: agents who work for a principal whose mission is closely aligned with their ideal mission, derive higher intrinsic benefit and thus, ceteris paribus, exert more effort, than agents who work for a principal with a different mission. The authors show that a principal can save on monetary incentives if he is matched with an agent who shares his same mission preferences. In their setting, however, the job mission is assumed to be exogenous $\mathrm{f}^{6}$ and motivated agents vary in their mission preferences rather than in how much they care about the project mission. Furthermore, in their model, there are no informational asymmetries and the matching of principals and agents is derived by an analysis of stable matching rather than by the derivation of an optimal allocation mechanism. This paper contributes to this literature by studying an adverse selection problem in the presence of mission preferences and by endowing the principal with a non-monetary instrument, i.e. the

\footnotetext{
${ }^{4}$ This seems particularly relevant for those tasks that involve a certain level of creativity from the agent. Think for instance of a newspaper's director who needs to decide how much to pay his journalists and at the same time how much discretion to leave them in writing their articles. The newspaper may want to have strict rules on how articles should be written and on what topics should be covered. Journalists, on the other hand, may want to write on what interests them the most and be free to choose their writing style.

${ }^{5}$ Studies that have looked at optimal contracting when agents vary in their intrinsic motivation include Francois (2003), and Delfgaauw and Dur (2007, 2008).

${ }^{6}$ The authors only briefly discuss the possibility of relaxing the assumption of exogenous job mission but leave the detailed analysis for future work.
} 
choice of the project mission, to influence the agents' motivation of exerting effort.

More generally, the paper also relates to those studies that analyze non-monetary devices to screen and incentivize agents with non-standard preferences. Previous studies have emphasized the role of status incentives (Besley and Ghatak (2008)), workers' identity (Akerlof and Kranton 2005, 2008)), bonus contracts (Fehr et al. (2007)), recruitment of biased workers (Prendergast (2007, 2008), and reciprocal incentives (Englmaier and Leider (2012)).

Finally, the paper relates to the theoretical literature on delegation (e.g. Holmstrom (1984); Aghion and Tirole (1997); Alonso and Matouschek (2008); Armstrong and Vickers (2010); Frankel (2014)). This literature addresses the question of how to allocate the right to select actions or projects between a principal and an agent. In these models, however, ex-ante informational asymmetries between the principal and the agent, if any, do not refer to the agent's intrinsic motivation, but to the payoff-relevant state of the world or to the set of feasible projects.

In the benchmark model in Section 4, I show that under the optimal mechanism the principal makes a smaller compromise on the mission than the full information optimum. In other words, because the agents' intrinsic motivation levels are private information, it is optimal for the principal to set a project mission that is closer to his ideal mission - and thus more distant from the agent's preferences - compared to the case in which the principal could observe the agents' intrinsic motivation levels. As a consequence, the agent's effort is also lower. This distortion arises because the informational rent given to the agents with higher intrinsic motivation is increasing in the effort level of the agents with lower intrinsic motivation. This also implies that while under complete information the project mission is always closer to the agent's than to the principal's preferences, under asymmetric information this only holds true for the missions contracted with agents with sufficiently high intrinsic motivation levels. Finally, I show that the optimal mechanism can be implemented through a scoring auction $\left.{ }^{7}\right]$ where agents bid a proposal for the project mission and a payment, and whose scoring rule over-penalizes a noncompliance of the agent's proposal with the principal's ideal mission compared to the principal's utility function. Under this scoring auction, agents with higher intrinsic motivation levels bid a lower payment and a project mission that is more distant from the principal' ideal mission, compared to the agents with lower intrinsic motivation levels. This prediction is consistent with the existing empirical evidence on the bidding strategies used by profits and non-profits for the allocation of aid contracts.

\footnotetext{
${ }^{7} \mathrm{~A}$ scoring auction is a multi-dimensional auction that requires to bid on other variables in addition to the price. Bids are evaluated by a scoring rule designed and announced ex-ante by the auctioneer. The bidder with higher total score wins.
} 
In Section 5, I derive the optimal mechanism if the project mission must be chosen prior to the allocation of the project. This means that the principal cannot condition the mission on the agent's type. I show that an increase in competition, defined as the number of agents competing for the project, brings the principal to align the mission more with the agent's preferences, which increases his effort. Also, I show that the project mission under this simpler mechanism is better aligned with the agents' preferences compared to the expected project mission of the mechanism described above, in which the principal can condition both the mission and the payment on the agent's type. This stems from the fact that, in the scoring auction, the agents are also competing along the mission dimension and these competitive forces drive up their expected ideological compromise 8

In Section 6, I analyze the same optimal contracting problem assuming the presence of budget constraints and one agent only. In this setting the principal's payment represents the budget available to the agent to develop the project, and the agent's effort can now be interpreted as the agent's ex-post monetary investment in the project. This means that the payment acts as an upper bound on the agent's investment, as it must cover its costs. This extension captures those situations in which a principal allocates a budget to an agent with expertise, who should then invest it in a public project. As contracts are incomplete, the amount of the budget that the agent will actually invest - rather than keep for personal consumption or waste - depends on the agent's intrinsic motivation and on the extent to which the mission of the project reflects his preferences. I show that in this setting the optimal contract is a pooling contract: the optimal project mission and the optimal payment are not contingent on the agent's intrinsic motivation level. In other words, it is not optimal for the principal to screen the agent. Compared to the main model, the principal can no longer save on payments by better aligning the project mission with the agent's ideal mission. As the project mission gets closer to the agent's ideal mission, the agent's investment increases, but only to the extent allowed by the payment-budget. That is, the ideological and the financial compensation are complements rather than substitutes. I show that for a separating equilibrium to be implementable, types with low intrinsic motivation levels must receive very high financial rents. This turns out not to be optimal for the principal.

\footnotetext{
${ }^{8}$ While the effect of competition in private good procurement has been widely studied, no equivalent evidence exists in the context of social good provision with motivated agents. Theoretical contributions on the effect of competition between motivated agents have focused on private fund-raising (Aldashev and Verdier (2010); Aldashev et al. (2013)), matching with mission-oriented organizations (Besley and Ghatak (2005, 2006)), organizational choice (Ghatak and Mueller (2011, 2013)) and corporate culture (Kosfeld and von Siemens (2011)). An exception is Chau and Huysentruyt (2006), which studies non-profits' competition for a procurement contract. The authors show that a competitive tender for the allocation of public funds leads to an ideological compromise between the missions of the principal and the contracted non-profit. Their paper, however, does not derive the optimal mechanism and does not study the effect of competition by varying the number of competitors.
} 


\section{The Model}

Consider the following environment: a principal needs to allocate a contract to one among $n$ motivated agents for the realization of an indivisible project. The contract specifies a project mission, $m$, and a payment, $p$. The agent who is allocated the contract $(m, p)$ will then exert a level of effort, $e$, to develop the project. I assume the output of the project to be equal to the agent's effort. This coincides with assuming a linear production function $Y(e)=e$. Alternatively, $e$ can be interpreted as the probability of a high output. To avoid confusion, throughout the paper I will only refer to the agent's effort rather than to the project's output. Consistent with many standard agency models for the provision of public goods $!^{9}$ due to contracts' incompleteness and non-enforceability of effort, the latter is assumed to be observable ex-post but not contractible.

Agents vary in their innate intrinsic motivation level, $\theta$. Everything else being equal, agents with higher $\theta$ derive higher intrinsic benefit from putting effort into the project. Each agent only knows his own intrinsic motivation; the other agents and the principal perceive types as being independently drawn from a distribution function $F($.$) on the interval [0,1]$. $F($.$) is$ assumed to satisfy the monotone hazard rate property, i.e. $\partial[(1-F(\theta)) / f(\theta)] / \partial \theta<0$.

The agents and the principal are endowed with different observable mission preferences, i.e. they disagree on what the project mission should be. Let's define by $m_{D}$ the ideal mission of the principal and by $m_{i}$ the ideal mission of agent $i$. I present here the simplest version of the model: $m, m_{D}$, and $m_{i}$ are one-dimensional variables and missions preferences are homogenous across agents, i.e. $m_{i}=m_{A} \forall i$ 10 For the sake of notational simplicity let me standardize the missions' values to $m_{A}>m_{D} \geq 0$. It follows that the value taken by the project mission must lie between $m_{D}$ and $m_{A}$, i.e. $m_{A} \geq m \geq m_{D}$

Formally, the agents' and the principal's preferences can be represented as follows. The

\footnotetext{
${ }^{9}$ I refer the reader to Francois and Vlassopoulos (2008) for a review of this literature

${ }^{10}$ As mentioned in the introduction, relaxing the assumption of agents' homogenous mission preferences would lead to a multidimensional screening problem that is not tractable in this setting. Because of the endogeneity of the direction in which the incentive compatibility constraints bind, the optimal mechanism design problem where private information is multidimensional is hardly tractable and, if it is, it depends finely on the exact parameters of the problem and cannot be implemented by standard auction format or other practical and simple contracting procedures, as also stated in Asker and Cantillon (2010). Therefore, it goes beyond the scope of this analysis.

${ }^{11}$ As an explanatory example, suppose that the principal and the agents disagree on beneficiaries' targeting: while the principal would like an equal representation of beneficiaries from ethnic group A and from ethnic group B, the agents are only interested in helping ethnic group A. These mission preferences can be represented by defining the project mission as the percentage of beneficiaries from ethnic A. Then $m_{A}$ will correspond to 100 and $m_{D}$ to 50 .
} 
utility of agent $i, i=1, \ldots, n$ from winning the contract is given by

$$
U_{i}\left(e_{i} ; m, p\right)=p+\theta_{i} G\left(m_{A}-m\right) e_{i}-\psi\left(e_{i}\right)
$$

$G\left(m_{A}-m\right)$ represents an ideology function, with properties $G^{\prime}\left(m_{A}-m\right)<0, G^{\prime}(0)=0$, $G^{\prime \prime}\left(m_{A}-m\right)<0$. It is a function that increases as $m$ gets closer to the agent's ideal mission $m_{A}$, or, more intuitively, it is a function that decreases in the distance between $m$ and $m_{A}$, i.e. in the agent's ideological compromise. Notice that the intrinsic benefit derived from exerting effort - the second term in (1) - results from the interaction between the agent's exogenous intrinsic motivation level and the extent to which the project mission is aligned with his own ideal mission. As $m$ gets closer to $m_{A}$, the utility that the agent gets from putting effort into the project increases. This increase is higher the larger is $\theta_{i}$, i.e. agents with higher intrinsic motivation get a higher intrinsic benefit from a decrease in their ideological compromise. $\psi\left(e_{i}\right)$ represents the standard disutility of effort, $\psi^{\prime}>0, \psi^{\prime \prime}>0$. To allow for an explicit solution, I will assume that $\psi\left(e_{i}\right)=\frac{1}{2} e_{i}^{2}$. If the agent is not allocated the project, he receives a reservation utility $\bar{u}$.

The utility of the principal from contracting with agent $i$ is

$$
V_{D}\left(m, p ; e_{i}\right)=\theta_{D} G\left(m-m_{D}\right) e_{i}-p
$$

where $\theta_{D}$ is a fixed parameter capturing how much the principal cares about the project's output. $G($.$) is the same function as for the agents in equation (1), but centered at m_{D}$ rather than at $m_{A}$. If the principal does not allocate the project, his utility is zero.

Figure (1) provides an example of the agents' and the principal's ideology functions. Notice that, in principle, $G($.$) can also take negative values. If the project mission is too far away$ from one's ideal mission, there are intrinsic costs rather than intrinsic benefits associated with the development of the project. It follows that a necessary condition for the contract to be allocated is that the principal's and the agents' ideal missions are sufficiently close. Graphically, this means that the ideology function of the principal, $G\left(m-m_{D}\right)$, and the ideology function of the agents, $G\left(m_{A}-m\right)$, take a positive value at their crossing point. In the remainder of the paper, I will simply assume, as in Figure (1), that $G\left(m_{A}-m_{D}\right)>0$.

It is worth mentioning that the model naturally extends to heterogeneous $k$-dimensional missions, provided that the distance between the $k$-dimensional vector $m_{D}$ and the $k$-dimensional vector $m_{i}$ is kept constant across agents: $d\left(m_{D}, m_{i}\right)=\left\|m_{D}-m_{i}\right\|=\bar{d} \quad \forall i$. In such a multidimensional setting, the principal would not contract a specific project mission $m$ but rather a maximal allowed distance between the project mission and his own ideal mission, $d\left(m_{D}, m\right)$. It follows that once the contract has been allocated, the winning agent would be free to implement 


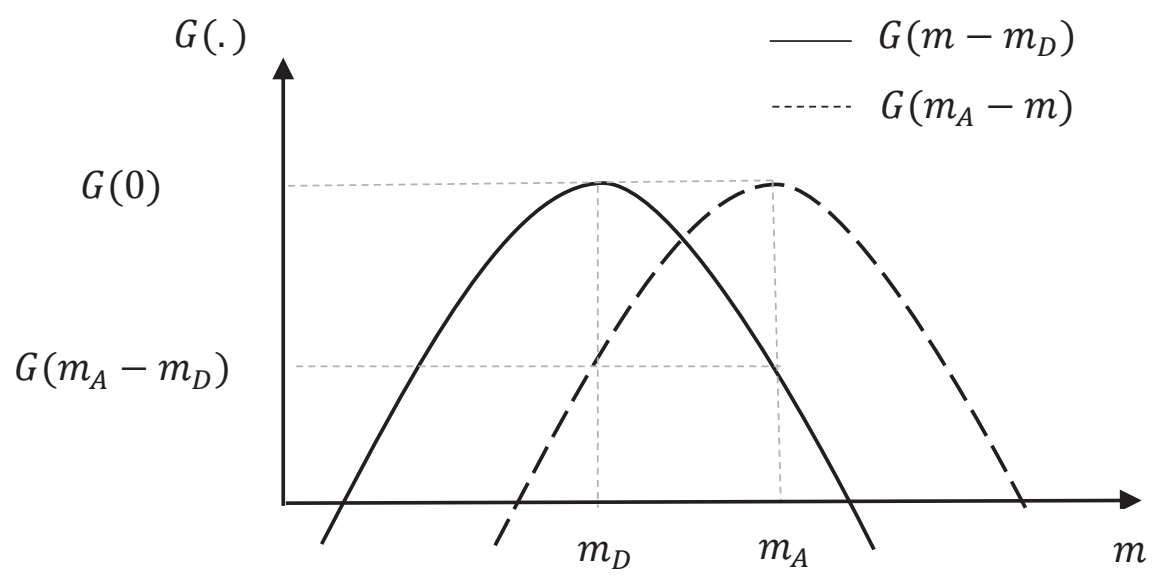

FIGURE 1

Ideology Functions

any project mission $m \in \mathbf{R}^{k}$ whose distance from the principal's ideal mission is equal or smaller than the distance allowed in the contract. In practice, the choice of $d\left(m_{D}, m\right)$ would translate into a number of binding conditions about the project's characteristics that will be specified in the contract. The higher the number and $\backslash$ or the stronger the conditions, the smaller is $d\left(m_{D}, m\right)$. What is not specified in the contract would be left to the agent's discretion. Therefore, the contract can also be interpreted as one that allocates control over the project's design between the winning agent and the principal.

Given the contract $(m, p)$, agent $i$ chooses an effort level equal to

$$
e_{i}^{*}\left(m, \theta_{i}\right)=\theta_{i} G\left(m_{A}-m\right)
$$

This effort function is known to the principal. However, since $\theta_{i}$ is not observable, at the time of offering the contract the principal does not know the effort level that the agent will put into the project.

\section{Full Information Optimum}

Before proceeding to the model with asymmetric information, I characterize the full information optimum, which already generates some relevant insights. If $\theta_{i}$ were observable, the principal would select the agent with the highest intrinsic motivation level, choose the project mission that maximizes total surplus, and set the payment to make the agent's participation constraint 
bind, $U_{i}=\bar{u}$. More specifically, under complete information the optimal mission $m^{*}\left(\theta_{i}\right)$ and the optimal payment $p^{*}\left(\theta_{i}\right)$ satisfy respectively:

$$
\begin{gathered}
\frac{\theta_{i}}{\theta_{D}}=\frac{G^{\prime}\left(m^{*}-m_{D}\right)}{G^{\prime}\left(m_{A}-m^{*}\right)}-\frac{G\left(m^{*}-m_{D}\right)}{G\left(m_{A}-m^{*}\right)} \\
p^{*}=\bar{u}-\frac{1}{2} \theta_{i}^{2} G\left(m_{A}-m^{*}\right)^{2}
\end{gathered}
$$

This solution has two important implications. First, comparative statics reveals that $m_{A}-$ $m_{i}^{*}\left(\theta_{i}\right)$ is decreasing in $\theta_{i}{ }^{12}$ That is, the higher is the agent's intrinsic motivation level, the closer is project mission to the agent's ideal mission. This is not surprising as it follows directly from the interaction between the agents' ideology function and the intrinsic motivation level $\theta_{i}$. Agents with higher intrinsic motivation levels are more responsive to a decrease in their ideological compromise, both in terms of a higher increase in their level of effort and of a higher increase in the intrinsic benefit that they derive from it. It follows that the higher is $\theta_{i}$, the more the principal can save on payments by moving the project mission towards the agents' ideal mission. Essentially, the principal is giving an ideological compensation to highly motivated agents, and a financial compensation to agents with lower intrinsic motivation.

Second, under complete information the principal bears the biggest ideological compromise, that is, the project mission is always closer to the agent's ideal mission than to the principal's one ${ }^{13}$ The intuition for this result is simple. The principal's surplus consists of the product of two factors: the agent's level of effort put into the project and how much the principal values that level of effort. This product is, thus, maximized when the project mission is half way between the principal's ideal mission and the agent's ideal mission. On the contrary, the agent's surplus is maximized when the project mission is equal to the agents' ideal one. It follows, that the socially optimal mission is closer to the agent's than to the principal's preferences. In other words, by better aligning the project mission with the agent's ideal mission, the principal saves on the payments due to the agent.

Finally, it is worth mentioning that in a model in which the agents were varying in their ability, i.e. cost of exerting effort, rather than in the degree to which they care about the project mission, we would not obtain the same results. Indeed, in that case, agents with higher

\footnotetext{
${ }^{12}$ To see this, notice that if $\theta_{i}$ increases, the LHS in equation (4) increases, so the RHS in equation (4) must also increase, which means that either $G^{\prime}\left(m_{i}-m_{D}\right) / G^{\prime}\left(m_{A}-m_{i}\right)$ increases or $G\left(m_{i}-m_{D}\right) / G\left(m_{A}-m_{i}\right)$ decreases, or both. Since $G(x)$ is decreasing in $x, G\left(m_{i}-m_{D}\right) / G\left(m_{A}-m_{i}\right)$ gets smaller as $m_{A}-m_{i}$ decreases and $m_{i}-m_{D}$ increases. Similarly, since $G(x)$ is decreasing and concave, $G^{\prime}\left(m_{i}-m_{D}\right) / G^{\prime}\left(m_{A}-m_{i}\right)$ increases as $G^{\prime}\left(m_{i}-m_{D}\right)$ decreases (i.e. becomes more negative) and $G^{\prime}\left(m_{A}-m_{i}\right)$ increases (i.e. becomes less negative), that is, as $m_{A}-m_{i}$ decreases and $m_{i}-m_{D}$ increases. This implies that $m_{i}^{*}\left(\theta_{i}\right)$ is increasing.

${ }^{13}$ To see this, notice that because the LHS in equation (4) is always positive, $G\left(m_{A}-m\right) / G^{\prime}\left(m_{A}-m\right) \leq$ $G\left(m-m_{D}\right) / G^{\prime}\left(m-m_{D}\right)$. Since $G(x)$ is decreasing and concave, this implies that $m_{A}-m \leq m-m_{D}$. Mind, however, that this result would not necessarily hold if the principal and the agents had different ideology functions $G($.$) .$
} 
ability would still exert more effort than agents with lower ability, but the benefit they would derive from any single unit of effort would be the same as other agents. This leads to a first best project mission that is independent of the agent's type. Furthermore, the project mission would be better aligned with the preferences of the party who has a higher valuation for it.

However, the principal cannot observe $\theta_{i}$. Thus, to select and incentivize an agent he uses the mechanism explained below. Without loss of generality, throughout the remainder of the paper I will set $\bar{u}=0$.

\section{Optimal Mechanism}

Without loss of generality, I restrict my attention to direct and incentive compatible mechanisms. That is, I look for a mechanism that specifies a probability of winning the project $q_{i}($.$) ,$ a project mission $m_{i}($.$) , and a payment p_{i}($.$) as functions of the agents' reported intrinsic moti-$ vation levels $\left(\hat{\theta}_{1}, \ldots, \hat{\theta}_{n}\right)=\hat{\theta}$, and that induces a truth-telling Bayesian Nash equilibrium, $\hat{\theta}=\theta$. For sake of notational simplicity, let $q_{i}\left(\theta_{i}\right), m_{i}\left(\theta_{i}\right)$ and $p_{i}\left(\theta_{i}\right)$ define, respectively, $E_{\theta_{-i}} q_{i}(\theta)$, $E_{\theta_{-i}} m_{i}(\theta)$ and $E_{\theta_{-i}} p_{i}(\theta)$.

The principal's optimization problem under incomplete information is then

$$
\max _{q_{i}(.), m_{i}(.), p_{i}(.)} E_{\theta}\left(\sum_{i=1}^{n} q_{i}(\theta) \theta_{D} G\left(m_{i}(\theta)-m_{D}\right) e_{i}^{*}-p_{i}(\theta)\right)
$$

subject to

$$
\begin{gathered}
\theta_{i} \in \arg \max _{\hat{\theta}_{i} \in \Theta} U_{i}\left(\hat{\theta}_{i}, \theta_{i}\right)=E_{\theta_{-i}}\left(p_{i}\left(\hat{\theta}_{i}, \theta_{-i}\right)+q_{i}\left(\hat{\theta}_{i}, \theta_{-i}\right) \theta_{i} G\left(m_{A}-m_{i}\left(\hat{\theta}_{i}, \theta_{-i}\right)\right) e_{i}^{*}-\frac{1}{2} e_{i}^{* 2}\right) \\
U_{i}\left(\theta_{i}\right) \geq 0 \\
e_{i}^{*}=\theta_{i} G\left(m_{A}-m_{i}(\theta)\right) \\
\sum_{i=1}^{n} q_{i}(\theta) \leq 1 \text { and } q_{i}(\theta) \geq 0 \text { for any } \theta, i=1, \ldots, n .
\end{gathered}
$$

where $U_{i}\left(\hat{\theta}_{i}, \theta_{i}\right)$ is the expected utility of agent $i$ when he reports his intrinsic motivation level to be $\hat{\theta}_{i}$ and all the other agents report their intrinsic motivation levels truthfully, and where $U_{i}\left(\theta_{i}\right)$ is the agent's $i$ expected utility when telling the truth. The incentive compatibility constraint in (7) then imposes that $U_{i}\left(\hat{\theta}_{i}, \theta_{i}\right)$ is maximized at $\hat{\theta}_{i}=\theta_{i}$, that is, it should be optimal for agent $i$ to report his type truthfully. Equations (8), (9), (10) represent, respectively, the individual rationality constraint, the agent's ex-post optimal level of effort, and the basic properties of the probability function. The solution to this problem leads to the first proposition: 
Proposition 1 Under the optimal mechanism:

a) The project is allocated to the agent with the highest intrinsic motivation:

$$
q_{i}^{*}(\theta)= \begin{cases}1 & \text { if } \theta_{i}>\max _{\forall j \neq i} \theta_{j} \\ 0 & \text { otherwise }\end{cases}
$$

b) The project mission contracted with agent $i$ satisfies:

$$
\frac{\theta_{i}-2 \frac{1-F\left(\theta_{i}\right)}{f\left(\theta_{i}\right)}}{\theta_{D}}=\frac{G^{\prime}\left(m_{i}^{*}-m_{D}\right)}{G^{\prime}\left(m_{A}-m_{i}^{*}\right)}-\frac{G\left(m_{i}^{*}-m_{D}\right)}{G\left(m_{A}-m_{i}^{*}\right)}
$$

c) The expected payment of agent $i$ satisfies:

$$
p_{i}^{*}\left(\theta_{i}\right)=\int_{0}^{\theta_{i}} E_{\theta_{-i}}\left(q_{i}\left(t_{i}, \theta_{-i}\right) t_{i} G\left(m_{A}-m_{i}\left(t_{i}, \theta_{-i}\right)\right)^{2}\right) d t_{i}-E_{\theta_{-i}}\left(q_{i}(\theta) \frac{1}{2} \theta_{i}^{2} G\left(m_{A}-m_{i}(\theta)\right)^{2}\right)
$$

Proof. See Appendix.

Proposition 1 deserves some comments. First, notice that the project is always allocated to the agent who has the highest intrinsic motivation level. Thus, there is no exclusion of types. Second, and more importantly, notice that equation (12) is equal to equation (4) with the additional negative term $-2\left(1-F\left(\theta_{i}\right)\right) / f\left(\theta_{i}\right)$ on the LHS. This implies that, with the exception of the project mission of the highest type in the distribution, the project missions of all the other types are distorted towards the principal's ideal mission compared to the full information optimum. As a consequence, the ex-post level of effort of the winning agent is also lower 14 This inefficiency arises because the informational rent that the principal must pay the agents with higher intrinsic motivation to prevent them from imitating agents with lower intrinsic motivation is a decreasing function of the ideological compromise of the agents with lower intrinsic motivation - as the first term in equation (13) suggests. Thus, by increasing the ideological compromise of the latter beyond the full information optimum, the principal saves on the informational rents. The project mission of the highest type is not distorted because no other type wants to imitate the highest type. Proposition 1 also implies that, contrary to the full information optimum, agents with $\theta_{i} \leq 2\left(1-F\left(\theta_{i}\right)\right) / f\left(\theta_{i}\right)$ contract a project mission that is closer to the principal's ideal mission than to their own.

Notice, furthermore, that given the regularity assumption about $F($.$) , the LHS of equation$ (12) is still increasing in $\theta_{i}$. Thus, the higher is the intrinsic motivation level of the winning

\footnotetext{
${ }^{14}$ This is consistent with the standard adverse selection result of "no distortion at the top" and with previous theoretical literature with non-motivated agents and explicit incentive schemes. In a setting with both adverse selection and moral hazard, Laffont and Tirole (1987) and McAfee and McMillan (1987) show that under the optimal mechanism the level of effort is lower than under the full-information optimum.
} 
agent, the closer is the project mission to his ideal mission, the lower is the payment, and the higher is his ex-post level of effort.

Finally, the higher is the weight that the principal attributes to output, $\theta_{D}$, compared to payments, the closer is the project mission to the prefect mid-way compromise, $\frac{m_{D}+m_{A}}{2}$. This holds true for all agent's intrinsic motivation levels. So in other words, as $\theta_{D}$ increases, the optimal contract $\left(m_{i}^{*}\left(\theta_{i}\right), p_{i}^{*}\left(\theta_{i}\right)\right)$ "converges" towards a pooling contract with mission $\frac{m_{D}+m_{A}}{2}$.

\subsection{Implementation}

How can the optimal mechanism be implemented in practice? By applying the results in Che (1993) to this model, I derive the next proposition:

Proposition 2 The optimal outcome can be implemented through a first-or second-score auction whose scoring rule over-penalizes a non-compliance with the principal's ideal mission compared to the principal's (true) utility function.

Proof. See Appendix.

A scoring auction is a multi-dimensional auction where agents bid on both the price and the project mission, and bids are evaluated by a scoring rule designed and announced ex-ante by the principal. The bidder with higher total score wins. More specifically, under the first-score auction the winner develops the project with the offered mission at the offered price. In the second score auction the winner is required to match the highest rejected score in the auction - with no additional constraints attached on the combination of mission-price.

A scoring rule specifies the weights that are given to the price and to the mission in calculating the bidder's score. Proposition 2 suggests that the optimal scoring rule induces the agents to bid a project mission that is closer to the principal's ideal mission than under the full information optimum. This naturally follows from Proposition 1. In practice, this means that the optimal scoring rule includes an additional argument to the true utility function of the principal that subtracts a higher number of points as the distance between $m$ and $m_{D}$ increases. This argument represents the informational rent due by the principal to the agent in order to satisfy the incentive compatibility constraint 15

Consistent with the model, public and international organizations such as EuropeAid, USAID, the UK's Department for International Development, and the World Bank's International Development Association, often use scoring auctions to allocate aid contracts: In practice, at

\footnotetext{
${ }^{15}$ See the Appendix for a mathematical expression of the optimal scoring rule.
} 
the launch of the tender, these organizations release the project's "Terms of Reference" (TOR) along with the scoring rule that will be adopted to evaluate each bid. The TOR is a document that describes in details the ideal project mission from these organizations' point of view. In terms of this model, it means that they announce $m_{D}$. Then, each competing candidates bid a price and a proposal on the project's design and characteristics. Finally, the procurer's designed scoring rule assigns a score to the offered price and to each aspect of the proposal on the extent to which it conforms with the specified TOR. The bidder with highest total score wins.

\subsection{Empirical evidence}

The model fits some recent empirical evidence regarding the bidding strategies used by profits and non-profits in scoring auctions for the allocation of aid contracts by the UK's Department of International Development (DFID). The data set analyzed in Huysentruyt (2011) was collected and constructed by the author at the DFID's office in Scotland. This data set includes detailed information about all the 457 aid service contracts that were allocated through scoring auctions between the period 1998 and 2003, including the terms of reference as well as the 1,222 bids that were made for these contracts. Among other things, the paper looks at how bidding strategies, contract outcomes and participation in specific tenders vary between profits and non-profits. The main results in Huysentruyt (2011) can be summarized as follows:

Fact 1 Non-profits make bids that score on average 4 to 6 percentage points worse on their compliance with the DFID's terms of reference (TOR) relative to for-profits (holding the tender constant).

Fact 2 The overall prices proposed by non-profits are approximately $60 \%$ cheaper, on average, than the prices proposed by for-profits (holding the tender constant).

These results are consistent with the model if we reasonably assume that workers in nonprofit organizations have on average a higher intrinsic motivation than workers in for-profit organizations. Agents with higher intrinsic motivation are willing to sacrifice financial gains in favor of a higher level of control over the project mission. Therefore, they will bid a lower price for developing the project and will bid a project mission that is more distant from the principal's ideal mission. On the other hand, agents with lower intrinsic motivation prefer to comply more with the principal's ideal mission in order to receive higher payments. As a consequence, they will bid a higher price for developing the project and will bid a project mission that is closer to the principal's ideal mission. So overall, highly motivated agents are more likely to score less 
on the mission dimension and more on the financial dimension than agents with low intrinsic motivation 16

\section{Optimal Mechanism with Ex-ante Fixed Mission}

In this section, I analyze a simpler mechanism in which the project mission is fixed prior to the allocation of the project and, therefore, the agents are only screened based on the financial dimension. I then compare this simpler mechanism to the one described above. The optimization problem is the same as the one in Section 4, with the exception that now the project mission $m$ cannot be conditioned on the agent's type $\theta_{i}$ :

$$
\max _{q_{i}(.), m, p_{i}(.)} E_{\theta}\left(\sum_{i=1}^{n} q_{i}(\theta) \theta_{D} G\left(m-m_{D}\right) e_{i}^{*}-p_{i}(\theta)\right)
$$

subject to

$$
\begin{gathered}
\theta_{i} \in \arg \max _{\hat{\theta}_{i} \in \Theta} U_{i}\left(\hat{\theta}_{i}, \theta_{i}\right)=E_{\theta_{-i}}\left(p_{i}\left(\hat{\theta}_{i}, \theta_{-i}\right)+q_{i}\left(\hat{\theta}_{i}, \theta_{-i}\right) \theta_{i} G\left(m_{A}-m\right) e_{i}^{*}-\frac{1}{2} e_{i}^{* 2}\right) \\
U_{i}\left(\theta_{i}\right) \geq 0 \\
e_{i}^{*}=\theta_{i} G\left(m_{A}-m\right) \\
\sum_{i=1}^{n} q_{i}(\theta) \leq 1 \text { and } q_{i}(\theta) \geq 0 \text { for any } \theta, i=1, \ldots, n .
\end{gathered}
$$

The solution to this problem leads to the following proposition:

Proposition 3 Under the optimal mechanism:

a) The project is allocated to the agent with the highest intrinsic motivation:

$$
q_{i}^{*}(\theta)= \begin{cases}1 & \text { if } \theta_{i}>\max _{\forall j \neq i} \theta_{j} \\ 0 & \text { otherwise }\end{cases}
$$

b)The ex-ante chosen project mission satisfies:

$$
\frac{E\left[Y_{2}^{2}\right]}{\theta_{D} E\left[Y_{1}\right]}=\frac{G^{\prime}\left(m^{*}-m_{D}\right)}{G^{\prime}\left(m_{A}-m^{*}\right)}-\frac{G\left(m^{*}-m_{D}\right)}{G\left(m_{A}-m^{*}\right)}
$$

\footnotetext{
${ }^{16}$ It is worth mentioning that this evidence does not prove that the DFID is actually using the optimal scoring auction. Other non-optimal scoring auctions may lead to similar results, as long as non-profits care more about the mission than for-profit organizations. Rather, this evidence suggests that the model in Section 2 is a good representation of the aid contracting environment and of the preferences of the actors involved in that environment.
} 
where $E\left[Y_{1}\right]$ and $E\left[Y_{2}^{2}\right]$ represent, respectively, the expected value of the first order statistic of n independently drawn $\theta_{i}$ and the expected value of the second order statistic of $n$ independently drawn $\theta_{i}^{2}$.

c) The expected payment of agent $i$ satisfies:

$$
p_{i}^{*}\left(\theta_{i}\right)=\int_{0}^{\theta_{i}} E_{\theta_{-i}}\left(q_{i}\left(t_{i}, \theta_{-i}\right) t_{i} G\left(m_{A}-m\right)^{2}\right) d t_{i}-E_{\theta_{-i}}\left(q_{i}(\theta) \frac{1}{2} \theta_{i}^{2} G\left(m_{A}-m\right)^{2}\right)
$$

d) The optimal mechanism can be implemented through a (reverse) price-only auction with the ex-ante chosen project mission in 20) .

Proof. See Appendix.

Depending on the specific assumptions about the ideology function $G($.$) and the distribution$ function $F($.), the optimal mechanism might lead to the exclusion of some types, which would be implementable by imposing a ceiling price in the price auction. Proposition 3 reports the results when the optimal mechanism does not lead to such exclusion, while the more general results can be found in the Appendix. But the main point is that while the principal always allocates the project if he can condition the mission on the winner's type, if the mission must be fixed ex-ante the optimal auction may require a ceiling price depending on the specification of the utility functions, so the project is not always allocated. The intuition for this difference is simple. The principal wants to prevent agents with higher intrinsic motivation from imitating agents with lower intrinsic motivation. If the mission must be fixed-ex ante, the principal can only use the price to screen the agents. In other words, he needs to give a higher financial rent to the agents with higher intrinsic motivation to make them reveal their true type. By excluding some of the agents with lower intrinsic motivation, the principal reduces the informational rents due to the higher types. If the mission can be determined with the allocation of the project, the principal has an additional instrument to prevent agents with higher intrinsic motivation from imitating the agents with lower intrinsic motivation. He can slightly increase the ideological compromise of the latter. So everything else being equal, in the mechanism with ex-ante fixed mission the principal needs to exclude a larger number of agents compared to the optimal mechanism where the project mission can be set ex-post.

More importantly, it can be seen that contrary to the mechanism described in Proposition 1 , the optimal project mission in 20 depends on the level of competition, $n$. The intuition for this difference is in the amount of information available to the principal at the time in which he chooses the project mission. In both settings, the effect of competition is to alter the distribution of the selected types, i.e. the expected intrinsic motivation of the winner is increasing in $n$. However, if the project mission can be determined with the allocation of 
the project, it can be conditioned on the winner's type. Therefore, once types are realized, competition plays no additional role. On the contrary, if the project mission must be fixed prior to the allocation of the project, the principal, at that point in time, has only information about the expected value of the winner's type. So the choice of the project mission is based on that expected value and the latter is an increasing function of the number of competing agents. Comparative statics then leads me to the next proposition:

Proposition 4 As competition increases, the project mission gets closer to the agent's ideal mission:

a) $\lim _{n \rightarrow 2} m_{A}-m^{*} \geq \lim _{n \rightarrow \infty} m_{A}-m^{*}$

b) $\exists n_{0}$ such that $\forall n>n_{0}, m_{A}-m^{*}$ is strictly decreasing in $n$.

c) For the uniform and any power function distribution $F\left(\theta_{i}\right), m_{A}-m^{*}$ is strictly decreasing in $n$.

Proof. See Appendix.

Competition reduces the ideological compromise of the selected agent, and thus increases his effort level. The main intuition for Proposition 4 is the following. A higher number of competitors increases the expected intrinsic motivation of the winner, namely the expected value of the first order statistic of $n$ independently drawn $\theta_{i}$, but increases even more the expected intrinsic benefit from developing the project of the second lowest bidder, namely the expected value of the second order statistic of $n$ independently drawn $\theta_{i}^{2}$. The former affects output, while the latter affects the payment due by the principal to the winner. Thus, roughly speaking, an increase in $n$ shifts the weight in the principal's utility function from the valuation of output to the payment. Therefore, the higher is the level of competition, the higher is the utility that the principal can derive by saving on payments rather than by increasing his valuation of output. This can be achieved by moving the ex-ante chosen project mission closer to the agent's ideal mission.

Finally, by comparing the expected project mission across the two mechanisms I find the following:

Proposition 5 Projects whose mission is determined ex-ante lead to a smaller expected ideological compromise of the agents and thus, to a higher expected level of effort, than projects whose mission is determined with its allocation.

Proof. See Appendix. 
Proposition 5 also holds when comparing the optimal scoring-auction with the optimal (reverse) second price-auction without ceiling price. Thus, the result does not depend on the exclusion condition. The intuition lies in the degree of competitiveness of the two mechanisms. When the project mission is fixed ex-ante, the agents are only competing along the price dimension. On the contrary, in the scoring auction the agents are competing along both the price and the ideological dimension, and the project mission is the result of competitive forces. This ideological competition between agents drives up their expected ideological compromise.

It is worth mentioning, however, that even if the agent's expected effort is higher when the project mission is fixed ex-ante, the principal is overall better off under the optimal mechanism described in Section 4. This raises the question of why price-only auctions with ex-ante chosen project mission are still used in practice to allocate some aid contracts. A reasonable potential explanation is that a scoring auction entails higher screening costs on the side of the principal, because a specific score has to be assigned to the mission dimension of each applicant's proposal, whereas under a price auction with ex-ante fixed mission, the principal only has to check that each proposal satisfies the conditions specified in the contract. Therefore, even if the principal gets an informational advantage by letting the mission be determined with the allocation of the project rather than fixing it ex-ante, as the number of competing agent increases, there is less uncertainty about the value of the intrinsic motivation of the winner, so this informational advantage decreases.

In the extreme case with $n \rightarrow \infty$, the principal knows with certainty the intrinsic motivation of the winner, so the optimal project mission will be the same whether it is set prior to, or with, the allocation of the project. In other words, if $n$ is sufficiently large, the optimal scoring auction and the optimal price auction yield the same expected utility to the principal. It follows that if the principal expects a large number of applicants, the expected loss in utility of fixing the project mission ex-ante can be lower than the expected savings in screening costs, making the price competition more appealing than the scoring auction. This is all the more true, the lower is $\theta_{D}$, that is, the lower is the weight that the principal assigns to output compared to the price. If $\theta_{D}$ is low, the principal mainly cares about lowering the price he has to pay for the project rather than about output. So in the presence of screening costs and high competition, it may not be worth running a scoring auction. Consistent with the stylized facts described below, this applies particularly well to the social goods that are covered by supply and work contracts (e.g. rental and hire products, building projects), whose implementation is, by nature, not very sensitive to ideological values. So the principal will mainly try to reduce the payment 17

\footnotetext{
${ }^{17}$ Indeed, the rental and hire of products or the procurement of a building project are less likely to involve strong mission preferences compared to the provision of social services, such as educational, health, or research projects.
} 


\subsection{Stylized facts and theoretical predictions}

Contrary to social service contracts, supply and work contracts in the aid sector are allocated through a standard price competition, with ex-ante fixed project mission ${ }^{18}$ In practice, fixing the project mission ex-ante is equivalent to specifying, in the TOR, a minimum set of conditions on the project's design that ought to be satisfied. Therefore, the conformity of the applicants' proposal to these conditions is only made on a YES/NO basis. No score is assigned. Only those applicants that satisfy a sufficient number of conditions will be allowed to bid for a price. Among those, the applicant that bid the lowest price is awarded the contract 19

The findings described in this section generates a number of testable predictions regarding the design of competitive tenders in the aid context:

Prediction 1 In tenders that allocate the procurement contract to the lowest bidder (price-only competition), there is a negative correlation between the number of competitors (in particular the number of non-profits) and the number of conditions in the TOR description that must be satisfied by the winner.

What is not specified in the TOR is left to the discretion of the agent. So moving the project mission closer to the agent's ideal mission translates into imposing fewer conditions in the TOR description. Thus, Proposition 4 suggests that under the optimal price-auction an increase in the expected number of competitors, by increasing the expected intrinsic benefit of developing project of the second lowest bidder, makes it optimal for the principal to impose fewer conditions on the project's design. By taking into account the further distinction between non-profits and for-profits, an expected increase in the relative participation of the former should also lead to an increase in the expected intrinsic benefit of the second lowest bidder. So Prediction 1 follows.

Prediction 2 The number of conditions listed in the TOR that must be satisfied by the winner is on average higher in those procurement contracts that are allocated through a scoring auction rather than through a price-only auction.

This prediction follows from Proposition 5, which suggests that on average the project mission is closer to the agent's ideal mission in price-only competitions rather than in competitions based on both price and mission.

\footnotetext{
${ }^{18}$ EuropeAid defines supply contracts those contracts that cover purchase, leasing, rental or hire of products. Work contracts cover the procurement of building or civil engineering projects.

${ }^{19}$ For more details see the Practical guide to contract procedures for European Union external actions.
} 


\section{Optimal Contract with Budget Constraints}

I now study the same optimal contracting problem, but in the presence of budget constraints. In this setting, the principal's payment represents the budget available to the agent to develop the project, and the agent's effort must now be interpreted as the agent's ex-post monetary investment in the project. There are, indeed, many natural situations in which a principal allocates a budget to an agent with expertise, who should then invest it in the public project. As contracts are incomplete, the amount of the budget that the agent will actually invest - rather than keep for personal consumption or waste - depends on the agent's intrinsic motivation and on the alignment between the project mission and his ideal mission. This extension is meant to capture, in particular, the contracting of public projects that are highly capital intensive, and where the agent has the expertise to make the investment but is not expected to financially contribute to the project. This is the case, for instance, in scientific and medical research projects or when the agent is an NGO with no access to independent resources.

Given the complexity of the analysis, I now assume that the principal faces only one agent of type $\theta \sim F(\theta)$. Furthermore, in order to keep the notation consistent with the rest of the paper, the model is still written and explained in terms of "effort" rather than "investment". But the latter interpretation remains the most appropriate.

Adding a budget constraint to the model has implications on the amount of effort that the agent can put into the project. This means that the agent cannot exert a level of effort whose cost is not covered by the principal's payment. Formally, this implies that

$$
e^{*}(m, p, \theta)=\min \left\{\theta G\left(m_{A}-m\right), \sqrt{2 p}\right\}
$$

The agent exerts the minimum between his optimal unconstrained level of effort - the one he would choose if he were not budget constrained - and the level of effort he can afford given the amount of funding received from the principal.

Before turning to the problem under asymmetric information, it is worth mentioning that if $\theta$ were observable by the principal, the optimal contract would imply an ideological compromise of the agent that is increasing in $\theta$ and a payment that is just enough to cover for the optimal unconstrained level of effort of the agent, i.e. $p^{*}(\theta)=\theta^{2} G\left(m_{A}-m(\theta)\right)^{2} / 2$. Indeed, contrary to Proposition 1, the principal can no longer save on payments by decreasing the agent's ideological compromise. As the project mission gets closer to the agent's ideal mission, the agent's effort increases, but so does the payment due by the principal. Thus, the negative relationship between payment and effort breaks down. The cost of effort is now entirely borne by the principal. It follows that the level of effort that maximizes the principal's utility is an internal solution: the higher is the weight that the principal attributes to output, $\theta_{D}$, the higher 
is the level of effort that maximizes his utility. The higher is $\theta$, the smaller is the ideological compromise that the principal needs to make to induce the agent to reach that level of effort.20

Under asymmetric information about $\theta$, the maximization problem faced by the principal becomes

$$
\max _{m(.), p(.)} E_{\theta}\left(\theta_{D} G\left(m(\theta)-m_{D}\right) e-p(\theta)\right)
$$

subject to

$$
\begin{gathered}
\theta \in \arg \max _{\hat{\theta} \in \Theta} U(\hat{\theta}, \theta)=p(\hat{\theta})+\theta G\left(m_{A}-m(\hat{\theta})\right) e^{*}-\frac{1}{2} e^{* 2} \\
U(\theta) \geq 0 \\
e^{*}=\min \left\{\theta G\left(m_{A}-m(\theta)\right), \sqrt{2 p(\theta)}\right\}
\end{gathered}
$$

First, notice that in this new setting the participation constraint in (24) is always satisfied because the principal cannot lower the payment to extract the agent's intrinsic utility from exerting effort. Thus, it can be omitted from the analysis. Second, with this new effort function, the utility functions are no longer separable in payment and the single crossing differences condition does not automatically hold. Therefore, the problem requires complicated mathematical analysis. For example, when looking at deviations, one should take into account that the agent could be in a different state compared to the case in which he reports his true type: the budget constraint might not be binding if the agent reports his type truthfully, but it may be binding if he reports a different type, and vice versa. Furthermore, the fact that a type is budget constrained under a specific contract does not imply that also other types will be budget constrained under that same contract.

The solution to the optimization problem is based on several Lemmas. Below, I provide an outline of the overall proof by summarizing shortly the main logical steps. I restrict my attention to contracts in which $m(\theta)$ is continuous.

First, I show that there does not exist an implementable mechanism where more than one type exerts his optimal unconstrained level of effort and for which the budget constraint binds.21 i.e. $p(\theta)=\theta^{2} G\left(m_{A}-m(\theta)\right)^{2} / 2$. I call the type for which this holds $\bar{\theta}$. Since type $\theta=0$ is never budget constrained, this leaves me with two possible cases: (1) $\bar{\theta}=1$, i.e. no agent is budget

\footnotetext{
${ }^{20}$ This relies on the assumption that $\theta_{D} G(0)>\theta G\left(m_{A}-m_{D}\right)$. That is, if $m=m_{D}$, the agent under-invests in effort with respect to the level that maximizes the principal's utility. If this was not the case, the principal could set his own preferred mission and pay the agent just enough to allow him to exert the amount of effort that maximizes his utility.

${ }^{21}$ This also shows that the full information optimum with budget constraints is not implementable.
} 
constrained; $(2) \bar{\theta} \in(0,1)$, i.e. types in $[0, \bar{\theta}]$ exert their optimal unconstrained level of effort, while types in $[\bar{\theta}, 1]$ are budget constrained ${ }^{22}$ Second, I show that in any interval of types that are not budget constrained, the strict single crossing differences condition holds. Therefore, in such intervals, $m_{A}-m^{*}(\theta)$ must be non-increasing in $\theta$. This applies to the full interval of types when $\bar{\theta}=1$, and in the interval $[0, \bar{\theta}]$ when $\bar{\theta} \in(0,1)$. Third, I show that there always exists a pooling contract that gives the principal a higher utility than any (full or partial) separating contract with decreasing $m_{A}-m^{*}(\theta)$. This holds for both $\bar{\theta}=1$ and $\bar{\theta} \in(0,1)$. Finally, I show that there exists no implementable mechanism in which $m_{A}-m^{*}(\theta)$ is increasing in $\theta$ in the interval of types that are budget constrained. That is, I rule out that $m_{A}-m^{*}(\theta)$ might be U-shaped when $\bar{\theta} \in(0,1)$. This proves that the optimal mechanism must be a pooling contract. Proposition 6 follows:

Proposition 6 The optimal mechanism is a pooling contract where (1) an agent with intrinsic motivation lower than $\bar{\theta}$ receives a financial rent and exerts his optimal unconstrained level of effort; (2) an agent with intrinsic motivation higher than $\bar{\theta}$ is budget constrained and receives no financial rents; (3) $\bar{\theta}>0$.

Proof. See Appendix.

In the presence of budget constraints, it is not optimal for the principal to screen the agent by offering a menu of contracts with different payments and project's missions. The intuition for this result is as follows: in the agent's utility function, the weight assigned to the project mission relatively to the financial payment is increasing in the agent's intrinsic motivation. Therefore, in order to screen the agent, the principal should offer to compensate higher types with a lower ideological compromise and lower types with a higher financial payment. However, the extent to which higher types can derive an intrinsic benefit from a project mission being close to their ideal mission depends on the amount of effort they are able to exert. Because of the budget constraints, the latter is bound to the payment. More specifically, the payment made by the principal acts as an upper bound for the level of effort that the agent can exert. This implies that the ideological and the financial compensation are complements rather than substitutes. For instance, a contract that specifies a low payment and a mission equal to the agent's ideal mission will still yield a low utility to a high type because the amount of effort that the latter can put into the project remains low. It follows that a separating equilibrium, to be implementable, requires low types to receive very high financial rents. As shown in the Appendix, this turns out not to be optimal for the principal. Proposition 6 suggests, moreover,

\footnotetext{
${ }^{22}$ It is indeed straightforward to show that under the optimal mechanism all types cannot be budget constrained. For more details see case $\bar{\theta} \rightarrow 0$ in the Appendix.
} 
that under the optimal pooling contract at least some agents with higher intrinsic motivations will always be budget constrained. This is to avoid the financial rent of the low motivated agents to be too high.

To see that the optimal mechanism would exhibit some pooling even in the presence of multiple agents, consider the participation and the incentive compatibility constraints of the lowest type, $\theta_{i}=0$. While in the benchmark model the participation constraint of the lowest type can be set to bind, leading to an incentive compatible probability of winning the contract equal to zero, in the presence of budget constraints the lowest type always derives some positive utility from winning the contract. This holds because, as explained above, the participation constraint in (24) slacks by definition, i.e. payments must be strictly positive. It follows that under any implementable mechanism, the lowest type must have a strictly positive probability of winning the contract. If this was not the case, the latter would be better off by imitating a higher type in order to receive a positive payment with a non-zero probability.

While a formal solution is derived for one agent only, this result still provides some intuition for why, calls for research grants may not take the exact form of scoring auctions with predefined scoring rules, but exhibit some characteristics similar to pooling contracts where the amount of funding that is awarded does not result endogenously from a bidding process but is, to a large extent, fixed ex-ante.

\section{Conclusion and discussion}

The paper makes several contributions. First, the paper contributes to the theoretical literature on optimal contracting with motivated agents by analyzing, for the first time, a mechanism design problem where the agents vary in their unobservable intrinsic motivation levels and are incentivized not by outcome-contingent rewards, but by the choice of the project mission. Contrary to previous studies, the agents' intrinsic benefit from developing a project is partly endogenous and dependent on the project mission.

Second, the paper contributes to the theoretical literature on delegation by identifying a new channel that can affect the delegation of a relevant decision from a principal to an agent. More precisely, in the model presented in this paper the principal's delegation of the choice of a project mission to an agent is lower than the socially optimal level because the principal cannot observe the agents' intrinsic motivation.

Third, the analysis provides policy recommendations to governments, international organizations and private foundations who pursue specific missions, on how to optimally design 
a competition for the allocation of a project. In particular, the analysis suggests that (1) in the absence of practical impediments, the project is best allocated through a scoring auction whose scoring rule assigns a higher weight to the mission dimension relatively to the procurer's true preference; (2) in price-only auctions, the higher is the expected number of applicants, the fewer conditions should be imposed in the project mission; (3) in the presence of budget constraints, less competitive mechanisms, e.g. posted grant with pre-determined amount of funding, direct negotiations or direct allocations to regular partners, may be more desirable than auction tenders to allocate the project.

More generally, the paper provides guidance to managers on how to optimally design compensation packages in situations where the workers care about the mission of their job and where outcome-contingent rewards are not available. More specifically, the analysis suggests that managers should offer a menu of contracts with different levels of discretion and payment. Agents with high intrinsic motivation will then self-select in those contracts that pay less but offer more discretion on how to solve their tasks or on how to implement their projects. Furthermore, in each of these contracts, the manager should offer a lower level of discretion than the one he would offer if he could observe the workers' intrinsic motivation. Finally, in the presence of budget constraints, the manager may want to offer the same contract to all workers.

Fourth, the paper contributes to the longstanding debate on the desirability of public-private partnerships for the delivery of social goods by providing insights on whose values are more likely to dictate the provision of these goods and under which circumstances. As discussed in Chau and Huysentruyt (2006), one may be worried that public values, such as laicism, might be undermined by delegating the provision of social services to, for instance, religious organizations. On the other hand, there is the concern that the state may interfere with nonprofits' goals and values, as the dependence on public funds is likely to make the non-profits vulnerable to political pressures. This paper shows that non-profits' missions are more likely to be compromised in the presence of informational asymmetries about the intrinsic motivation of their workers, when contracts are allocated through scoring auctions, and when competition within a price-only auction is low.

The model can be extended further in several ways. First, this paper focuses on a mechanism design problem where the agents vary in how much they value the mission dimension compared to the financial dimension when contracting the development of a project. An alternative approach would be to vary, instead, the distance between the agents' ideal missions and the principal's ideal mission. It is indeed plausible to assume that the mission preferences of some agents may be more aligned with the principal's ideal mission than others. Second, the present analysis presumes that monetary incentives to induce agent's effort are not available 
or desirable, for reasons outside the model. Such assumption could be relaxed to investigate situations where the principal has two instruments to motivate effort provision: a monetary incentive scheme that appeals to the agents' extrinsic motivation and the choice of the project mission that appeals to the agents' intrinsic motivation. Finally, the model generates a series of new theoretical predictions regarding the design of competitive tenders for the provision of social goods that are worth testing empirically. Given the relevant endogeneity issues present in field data, experimental data could provide valuable complementary evidence. All these extensions are left for future work. 


\section{Appendix}

\section{Proof of Proposition 1}

First, notice that by replacing the optimal ex-post level of effort in (9), the incentive compatibility constraint in (7) can be rewritten as

$$
U_{i}\left(\theta_{i}\right)=\max _{\hat{\theta}_{i} \in \Theta} E_{\theta_{-i}}\left(p_{i}\left(\hat{\theta}_{i}, \theta_{-i}\right)+q_{i}\left(\hat{\theta}_{i}, \theta_{-i}\right) \frac{1}{2} \theta_{i}^{2} G\left(m_{A}-m_{i}\left(\hat{\theta}_{i}, \theta_{-i}\right)\right)^{2}\right)
$$

By the Envelope Theorem, this implies:

$$
\begin{gathered}
U_{i}^{\prime}\left(\theta_{i}\right)=E_{\theta_{-i}}\left(q_{i}(\theta) \theta_{i} G\left(m_{A}-m_{i}(\theta)\right)^{2}\right) \\
U_{i}\left(\theta_{i}\right)=U_{i}(0)+\int_{0}^{\theta_{i}} E_{\theta_{-i}}\left(q_{i}\left(t_{i}, \theta_{-i}\right) t_{i} G\left(m_{A}-m_{i}\left(t_{i}, \theta_{-i}\right)\right)^{2}\right) d t_{i}
\end{gathered}
$$

The expected payment to agent $i$ is then

$p_{i}\left(\theta_{i}\right)=E_{\theta_{-i}} p_{i}(\theta)=p_{i}(0)+\int_{0}^{\theta_{i}} E_{\theta_{-i}}\left(q\left(t_{i}, \theta_{-i}\right) t_{i} G\left(m_{A}-m\left(t_{i}, \theta_{-i}\right)\right)^{2}\right) d t_{i}-E_{\theta_{-i}}\left(q_{i}(\theta) \frac{1}{2} \theta_{i}^{2} G\left(m_{A}-m_{i}(\theta)\right)^{2}\right)$

The participation constraint binds for the lowest type, thus $p_{i}(0)=0$. This proves equation (13).

Let now turn our attention to the principal's expected utility. After replacing the optimal effort level in (9), equation (6) becomes

$$
E\left(V_{D}\right)=E_{\theta}\left(\sum_{i=1}^{n} q_{i}(\theta) \theta_{D} \theta_{i} G\left(m_{i}(\theta)-m_{D}\right) G\left(m_{A}-m_{i}(\theta)\right)-p_{i}(\theta)\right)
$$

This can be rewritten as

$$
E\left(V_{D}\right)=\sum_{i=1}^{n} \int_{0}^{1}\left(E_{\theta_{-i}}\left(q_{i}(\theta) \theta_{D} \theta_{i} G\left(m_{i}(\theta)-m_{D}\right) G\left(m_{A}-m_{i}(\theta)\right)\right)-p_{i}\left(\theta_{i}\right)\right) f\left(\theta_{i}\right) d \theta_{i}
$$

Substituting the expected payment with equation 13 and interchanging the order of integration in the last term then gives

$$
\begin{aligned}
E\left(V_{D}\right)= & \sum_{i=1}^{n} \int_{0}^{1} E_{\theta_{-i}}\left(q_{i}(\theta) \theta_{D} \theta_{i} G\left(m_{i}(\theta)-m_{D}\right) G\left(m_{A}-m_{i}(\theta)\right)+q_{i}(\theta) \frac{\theta_{i}^{2}}{2} G\left(m_{A}-m_{i}(\theta)\right)^{2}\right. \\
& \left.-\frac{1-F\left(\theta_{i}\right)}{f\left(\theta_{i}\right)} q_{i}(\theta) \theta_{i} G\left(m_{A}-m_{i}(\theta)\right)^{2}\right) f\left(\theta_{i}\right) d \theta_{i}
\end{aligned}
$$


which can also be rewritten as

$$
\begin{aligned}
E\left(V_{D}\right)= & \sum_{i=1}^{n} E_{\theta}\left(q _ { i } ( \theta ) \left(\theta_{D} \theta_{i} G\left(m_{i}(\theta)-m_{D}\right) G\left(m_{A}-m_{i}(\theta)\right)+\frac{\theta_{i}^{2}}{2} G\left(m_{A}-m_{i}(\theta)\right)^{2}\right.\right. \\
& \left.\left.-\frac{1-F\left(\theta_{i}\right)}{f\left(\theta_{i}\right)} \theta_{i} G\left(m_{A}-m_{i}(\theta)\right)^{2}\right)\right) f(\theta) d \theta
\end{aligned}
$$

where $f(\theta)$ is the joint density of $\theta=\left(\theta_{1}, \ldots, \theta_{n}\right)$. Since the intrinsic motivation levels are independently distributed, $f(\theta)=f\left(\theta_{1}\right) \times f\left(\theta_{2}\right) \times \ldots \times f\left(\theta_{n}\right)$. By maximizing with respect to $m_{i}(\theta)$, I find the optimal mission as a function of the agents' $i$ intrinsic motivation level as in defined in equation 12 :

$$
\frac{\theta_{i}-2 \frac{1-F\left(\theta_{i}\right)}{f\left(\theta_{i}\right)}}{\theta_{D}}=\frac{G^{\prime}\left(m_{i}^{*}-m_{D}\right)}{G^{\prime}\left(m_{A}-m_{i}^{*}\right)}-\frac{G\left(m_{i}^{*}-m_{D}\right)}{G\left(m_{A}-m_{i}^{*}\right)}
$$

The assumption that $G^{\prime}(0)=0$ is sufficient for the second order conditions to be satisfied. This proves equation $(12){ }^{23}$ As far as the comparative statics are concerned, if $\theta_{i}$ increases, by the regularity condition of $F($.$) , the LHS in equation (12) increases, so the RHS in equation (12)$ must also increase, which means that either $G^{\prime}\left(m_{i}-m_{D}\right) / G^{\prime}\left(m_{A}-m_{i}\right)$ increases or $G\left(m_{i}-\right.$ $\left.m_{D}\right) / G\left(m_{A}-m_{i}\right)$ decreases, or both. Since $G(x)$ is decreasing in $x, G\left(m_{i}-m_{D}\right) / G\left(m_{A}-m_{i}\right)$ gets smaller as $m_{A}-m_{i}$ decreases and $m_{i}-m_{D}$ increases. Similarly, since $G(x)$ is decreasing and concave, $G^{\prime}\left(m_{i}-m_{D}\right) / G^{\prime}\left(m_{A}-m_{i}\right)$ increases as $G^{\prime}\left(m_{i}-m_{D}\right)$ decreases (i.e. becomes more negative) and $G^{\prime}\left(m_{A}-m_{i}\right)$ increases (i.e. becomes less negative), that is, as $m_{A}-m_{i}$ decreases and $m_{i}-m_{D}$ increases. This implies that $m_{i}^{*}\left(\theta_{i}\right)$ is increasing.

Let me define by $X\left(\theta_{i}\right)$ the equivalent of the virtual valuations in Myerson (1981):

$$
X\left(\theta_{i}\right)=\theta_{D} \theta_{i} G\left(m_{i}^{*}\left(\theta_{i}\right)-m_{D}\right) G\left(m_{A}-m_{i}^{*}\left(\theta_{i}\right)\right)+\theta_{i}\left[\frac{\theta_{i}}{2}-\frac{1-F\left(\theta_{i}\right)}{f\left(\theta_{i}\right)}\right] G\left(m_{A}-m_{i}^{*}\left(\theta_{i}\right)\right)^{2}
$$

By replacing (12) in (A-3), it becomes clear that the virtual valuations are positive for all $\theta_{i}$. This means that under the optimal mechanism - with $c=0$ - no type is excluded from the competition. To derive the optimal allocation rule, I look at the derivative of $X\left(\theta_{i}\right)$ :

$$
\frac{d X}{d \theta_{i}}=\frac{d X}{d m_{i}^{*}} \frac{d m_{i}^{*}}{d \theta_{i}}+\frac{\partial X}{\partial \theta_{i}}
$$

The product term is equal to zero by the FOC. Thus, we have

$$
X^{\prime}\left(\theta_{i}\right)=\theta_{D} G\left(m_{i}^{*}\left(\theta_{i}\right)-m_{D}\right) G\left(m_{A}-m_{i}^{*}\left(\theta_{i}\right)\right)+G\left(m_{A}-m_{i}^{*}\left(\theta_{i}\right)\right)^{2}\left[\theta_{i}\left(1-\frac{\partial \frac{1-F\left(\theta_{i}\right)}{f\left(\theta_{i}\right)}}{\partial \theta_{i}}\right)-\frac{1-F\left(\theta_{i}\right)}{f\left(\theta_{i}\right)}\right]
$$

\footnotetext{
${ }^{23}$ To rule out potential corner solutions, I assume that $\theta_{D}$ is large enough such that $\theta_{i}>2 \frac{1-F\left(\theta_{i}\right)}{f\left(\theta_{i}\right)}-$ $\theta_{D} G(0) / G\left(m_{A}-m_{D}\right), \forall \theta_{i}$.
} 
Rearranging the term above gives the following condition for the positive monotonicity of the virtual valuations:

$$
\theta_{i}>s\left(\theta_{i}\right)^{-1}\left(\frac{1-F\left(\theta_{i}\right)}{f\left(\theta_{i}\right)}-\frac{\theta_{D} G\left(m_{i}^{*}\left(\theta_{i}\right)-m_{D}\right)}{G\left(m_{A}-m_{i}^{*}\left(\theta_{i}\right)\right)}\right)
$$

where $s\left(\theta_{i}\right)=1-\partial\left[\left(1-F\left(\theta_{i}\right)\right) / f\left(\theta_{i}\right)\right] / \partial \theta_{i}$. From the monotone hazard rate property of $F($.$) ,$ we know that $\partial\left[\left(1-F\left(\theta_{i}\right)\right) / f\left(\theta_{i}\right)\right] / \partial \theta_{i}<0$, which implies that $0<s\left(\theta_{i}\right)^{-1}<1$. When $\left(1-F\left(\theta_{i}\right)\right) / f\left(\theta_{i}\right)<\theta_{D} G\left(m_{i}^{*}\left(\theta_{i}\right)-m_{D}\right) / G\left(m_{A}-m_{i}^{*}\left(\theta_{i}\right)\right)$ it is immediately clear that the condition in (A-4) is always satisfied. By replacing the LHS of A-4 with the FOC in (12), one can show that the monotonicity of the virtual valuations also holds when $\left(1-F\left(\theta_{i}\right)\right) / f\left(\theta_{i}\right)>$ $\theta_{D} G\left(m_{i}^{*}\left(\theta_{i}\right)-m_{D}\right) / G\left(m_{A}-m_{i}^{*}\left(\theta_{i}\right)\right)$ :

$$
2 \frac{1-F\left(\theta_{i}\right)}{f\left(\theta_{i}\right)}-\frac{\theta_{D} G\left(m_{i}^{*}-m_{D}\right)}{G\left(m_{A}-m_{i}^{*}\right)}+\overbrace{\theta_{D} \frac{G^{\prime}\left(m_{i}^{*}-m_{D}\right)}{G^{\prime}\left(m_{A}-m_{i}^{*}\right)}}^{+}>s\left(\theta_{i}\right)^{-1}\left(\frac{1-F\left(\theta_{i}\right)}{f\left(\theta_{i}\right)}-\frac{\theta_{D} G\left(m_{i}^{*}-m_{D}\right)}{G\left(m_{A}-m_{i}^{*}\right)}\right)
$$

Rearranging:

$$
\left(2-s\left(\theta_{i}\right)^{-1}\right) \frac{1-F\left(\theta_{i}\right)}{f\left(\theta_{i}\right)}-\left(1-s\left(\theta_{i}\right)^{-1}\right) \frac{\theta_{D} G\left(m_{i}^{*}-m_{D}\right)}{G\left(m_{A}-m_{i}^{*}\right)}+\theta_{D} \frac{G^{\prime}\left(m_{i}^{*}-m_{D}\right)}{G^{\prime}\left(m_{A}-m_{i}^{*}\right)}>0
$$

Since $0<s\left(\theta_{i}\right)^{-1}<1$ and $\left(1-F\left(\theta_{i}\right)\right) / f\left(\theta_{i}\right)>\theta_{D} G\left(m_{i}^{*}\left(\theta_{i}\right)-m_{D}\right) / G\left(m_{A}-m_{i}^{*}\left(\theta_{i}\right)\right)$, the expression above is always positive. This implies that the optima allocation rule is

$$
q_{i}^{*}(\theta)= \begin{cases}1 & \text { if } \theta_{i}>\max _{\forall j \neq i} \theta_{j} \\ 0 & \text { otherwise }\end{cases}
$$

This completes the proof of Proposition 124

\footnotetext{
${ }^{24}$ The monotonocity of $q_{i}^{*}$ and $m_{i}^{*}$ guarantee that the single crossing differences condition, $\partial U_{i}^{*} / \partial \hat{\theta}_{i} \partial \theta_{i}>0$, holds and, therefore, that the incentive compatibility constraint is satisfied.
} 


\section{Proof of Proposition 2}

Consider the following scoring rule:

$$
\begin{aligned}
S^{*}(m, p)= & \theta_{D} m_{0}^{-1}(m) G\left(m-m_{D}\right) G\left(m_{A}-m\right)-p-\theta_{D} \int_{v}^{m} \frac{\partial m_{0}^{-1}(s)}{\partial m} G\left(s-m_{D}\right) G\left(m_{A}-s\right) d s \\
& +\int_{v}^{m} \frac{1-F\left(m_{0}^{-1}(s)\right)}{f\left(m_{0}^{-1}(s)\right)} m_{0}^{-1}(s) 2 G\left(m_{A}-s\right) G^{\prime}\left(m_{A}-s\right) d s
\end{aligned}
$$

for $m \in\left[m_{0}(0), m_{0}(1)\right]$ and where $m_{0}($.$) is the optimal mission in equation (12) and v$ is any real number. From Lemma 1 in Che (1993), I know that under the first- and second-score auction with general scoring rule $S(m, p)$, each agent bids an $m$ that maximizes $S(m, p)+\frac{\theta_{i}^{2}}{2} G\left(m_{A}-m\right)^{2}$. Thus, with scoring rule $S^{*}(m, p)$ defined above, each agent chooses the mission that maximizes

$$
\begin{aligned}
Z\left(\theta_{i}, m\right)= & \theta_{D} m_{0}^{-1}(m) G\left(m-m_{D}\right) G\left(m_{A}-m\right)-p-\theta_{D} \int_{v}^{m} \frac{\partial m_{0}^{-1}(s)}{\partial m} G\left(s-m_{D}\right) G\left(m_{A}-s\right) d s \\
& +\int_{v}^{m} \frac{1-F\left(m_{0}^{-1}(s)\right)}{f\left(m_{0}^{-1}(s)\right)} m_{0}^{-1}(s) 2 G\left(m_{A}-s\right) G^{\prime}\left(m_{A}-s\right) d s+\frac{\theta_{i}^{2}}{2} G\left(m_{A}-m\right)^{2}
\end{aligned}
$$

By the product rule, the expression above can be rewritten as

$$
\begin{aligned}
Z\left(\theta_{i}, m\right)= & \int_{v}^{m} \theta_{D} m_{0}^{-1}(s)\left[G^{\prime}\left(s-m_{D}\right) G\left(m_{A}-s\right)-G\left(s-m_{D}\right) G^{\prime}\left(m_{A}-s\right)\right] \\
& +\frac{1-F\left(m_{0}^{-1}(s)\right)}{f\left(m_{0}^{-1}(s)\right)} m_{0}^{-1}(s) 2 G\left(m_{A}-s\right) G^{\prime}\left(m_{A}-s\right) d s-p+\frac{\theta_{i}^{2}}{2} G\left(m_{A}-m\right)^{2}
\end{aligned}
$$

Taking the derivative wrt $m$

$$
\begin{aligned}
\frac{\partial Z\left(\theta_{i}, m\right)}{\partial m}= & \theta_{D} m_{0}^{-1}(m)\left[G^{\prime}\left(m-m_{D}\right) G\left(m_{A}-s\right)-G\left(m-m_{D}\right) G^{\prime}\left(m_{A}-m\right)\right] \\
& +\frac{1-F\left(m_{0}^{-1}(m)\right)}{f\left(m_{0}^{-1}(m)\right)} m_{0}^{-1}(m) 2 G\left(m_{A}-m\right) G^{\prime}\left(m_{A}-m\right)-\theta_{i}^{2} G\left(m_{A}-m\right) G^{\prime}\left(m_{A}-m\right) \\
= & 0 \text { if } m=m_{0}\left(\theta_{i}\right)
\end{aligned}
$$

where $m_{0}\left(\theta_{i}\right)$ is the mission rule that satisfies the FOCs in (12). Thus, I have shown that the optimal mission is implemented by the modified scoring rule $S^{*}(m, p)$. Since under the first and second-score auction with scoring rule $S^{*}(m, p)$, both the allocation rule and the project mission are the same as under the optimal mechanism, the first-and second-score auctions with this optimal scoring rule give the same expected utility to the principal than the optimal mechanism. 


\section{Proof of Proposition 3}

I now show that the optimal mechanism when the project mission must be fixed ex-ante can be implemented through a second-price auction (with or without ceiling price). In a second price auction the principal's expected utility from a bidder with intrinsic motivation $\theta_{i} \geq \underline{\theta}$ is

$$
\begin{aligned}
E\left(V_{D}\right)= & \theta_{D} \theta_{i} G\left(m-m_{D}\right) G\left(m_{A}-m\right) F\left(\theta_{i}\right)^{n-1}+\frac{G\left(m_{A}-m\right)^{2}}{2} \underline{\theta}^{2} F(\underline{\theta})^{n-1} \\
& +\int_{\underline{\theta}}^{\theta_{i}} \frac{G\left(m_{A}-m\right)^{2}}{2} x^{2}(n-1) F(x)^{n-2} f(x) d x
\end{aligned}
$$

So the principal's overall expected utility is

$$
\begin{aligned}
E\left(V_{D}\right)= & \theta_{D} G\left(m-m_{D}\right) G\left(m_{A}-m\right)\left(1-F_{1}(\underline{\theta})\right) E\left(Y_{1} / Y_{1}>\underline{\theta}\right)+\frac{G\left(m_{A}-m\right)^{2}}{2} \underline{\theta}^{2} n F(\underline{\theta})^{n-1}(1-F(\underline{\theta})) \\
& +\frac{1}{2} G\left(m_{A}-m\right)^{2}\left(1-F_{2}(\underline{\theta})\right) E\left(Y_{2}^{2} / Y_{2}>\underline{\theta}\right)
\end{aligned}
$$

Taking the derivative of $E\left(V_{D}\right)$ with respect to $\underline{\theta}$ and rearranging gives

$$
2 \frac{1-F(\underline{\theta})}{f(\underline{\theta})}-2 \frac{\theta_{D} G\left(m-m_{D}\right)}{G\left(m_{A}-m\right)}-\underline{\theta} \leq 0
$$

If the expression above is negative $\forall \underline{\theta}$, then the second price auction should not have a ceiling price and the optimal mission satisfies the FOC in equation (20). If the expression above can hold with equality, the second price auction should have a ceiling price $p(\underline{\theta})$ and optimal mission $m$, where $m$ and $\underline{\theta}$ solve the following system of equations

$$
\begin{gathered}
2 \frac{1-F(\underline{\theta})}{f(\underline{\theta})}-2 \frac{\theta_{D} G\left(m-m_{D}\right)}{G\left(m_{A}-m\right)}-\underline{\theta}=0 \\
\frac{\left(1-F_{2}(\underline{\theta})\right) E\left(Y_{2}^{2} \mid Y_{2}>\underline{\theta}\right)+\underline{\theta}^{2} F(\underline{\theta})^{n-1}(1-F(\underline{\theta})) n}{\left(1-F_{1}(\underline{\theta})\right) E\left(Y_{1} \mid Y_{1}>\underline{\theta}\right) \theta_{D}}-\frac{G^{\prime}\left(m-m_{D}\right)}{G^{\prime}\left(m_{A}-m\right)}+\frac{G\left(m-m_{D}\right)}{G\left(m_{A}-m\right)}=0
\end{gathered}
$$

where $F_{1}($.$) and F_{2}($.$) are, respectively, the distribution function of the first and second highest$ order statistic of $n$ independently drawn $\theta$. So under the second price auction with ceiling price $p(\underline{\theta})$, the optimal allocation rule is

$$
q_{i}^{S P}(\theta)= \begin{cases}1 & \text { if } \theta_{i}>\max _{\forall j \neq i} \theta_{j} \text { and } \theta_{i}>\underline{\theta}^{S P} \\ 0 & \text { otherwise }\end{cases}
$$

Following the same steps as in the proof of Proposition 1, the principal's utility under the optimal mechanism can be rewritten as

$$
\begin{aligned}
E\left(V_{D}\right)= & \sum_{i=1}^{n} E_{\theta}\left(q _ { i } ( \theta ) \left(\theta_{D} \theta_{i} G\left(m-m_{D}\right) G\left(m_{A}-m\right)+\frac{\theta_{i}^{2}}{2} G\left(m_{A}-m\right)^{2}\right.\right. \\
& \left.\left.-\frac{1-F\left(\theta_{i}\right)}{f\left(\theta_{i}\right)} \theta_{i} G\left(m_{A}-m\right)^{2}\right)\right) f(\theta) d \theta
\end{aligned}
$$


The virtual valuations in the expression above are positive for those agents whose $\theta_{i}$ satisfies

$$
2 \frac{1-F\left(\theta_{i}\right)}{f\left(\theta_{i}\right)}-2 \frac{\theta_{D} G\left(m^{*}-m_{D}\right)}{G\left(m_{A}-m^{*}\right)}-\theta_{i} \leq 0
$$

Notice that the expression above coincides with inequality (A-6). Furthermore, for those $\theta_{i}$ that satisfies this equation, it can be check that the virtual valuations are increasing in $\theta_{i}$. This means that the allocation rule under the optimal mechanism is the same as under the second price auction: $q_{i}^{*}(\theta)=q_{i}^{S P}(\theta)$. This in turn implies that the expected utility of the principal under the second price auction is the same as under the optimal mechanism, and therefore so is the optimally chosen mission.

Finally, notice that by the Revenue Equivalence Theorem, the optimal mechanism can also be implemented through any (reverse) auction in the wide class of auctions that allocate the price to the lowest bidder, namely, first-price auction, all-pay auction, and so on. Indeed, since such auctions have the same allocation rule and yield the same expected payment to the seller, the optimal project mission chosen ex-ante will also be the same. 


\section{Proof of Proposition 4}

a) For any distribution function $F($.$) over the interval [0,1]$, it holds that

$$
\lim _{n \rightarrow \infty} \frac{E\left[Y_{2}^{2}\right]}{E\left[Y_{1}\right]} \geq \lim _{n \rightarrow \infty} E\left[Y_{2}\right]=1
$$

This gives us a lower bound for when competition is high. Furthermore, since:

$$
E\left[Y_{2}^{2}\right] \leq E\left[Y_{2} \cdot 1\right]=E\left[Y_{2}\right] \leq E\left[Y_{1}\right]
$$

it follows that $E\left[Y_{2}^{2}\right] / E\left[Y_{1}\right] \leq 1$ for any finite $n$.

b) Consider any distribution function $F($.$) over the interval [0,1]$. Then, a sufficient but not necessary condition for $d m^{*} / d n>0$ is $d E\left[Y_{1}\right] / d n-d E\left[Y_{2}^{2}\right] / d n<0$. After few mathematical steps you get

$$
S=E\left[Y_{1}\right]-E\left[Y_{2}^{2}\right]=\int_{0}^{1} n F(x)^{n-1} 2 x-F(x)^{n}(1+2 x(n-1)) d x
$$

Taking the derivative with respect to $n$ gives and rearranging gives

$$
\frac{d S}{d n}=\int_{0}^{1} F(x)^{n-1}\{2 x(1-F(x))(1+\log [F(x)] n)+\log [F(x)] F(x)(2 x-1)\} d x
$$

The overall sign of the expression above depends on the sign of the expression in the curly brackets. The last term is independent of $n$ while the first term gets more negative as $n$ increases. So there must exists a value of $n$, which I define $n_{0}$, such that for any $n \geq n_{0}$ the expression above is negative. Therefore, $d m^{*} / d n>0$ for any $n \geq n_{0}$.

c) I now show that for the uniform and any power function distributions, $E\left[Y_{2}^{2}\right] / E\left[Y_{1}\right]$ is strictly increasing in $n$. If $F($.$) is uniformly distributed, E\left[Y_{2}^{2}\right]=(n-1) n /(n+1)(n+2)$, and $E\left[Y_{1}\right]=n /(n+1)$. This gives $E\left[Y_{2}^{2}\right] / E\left[Y_{1}\right]=(n-1) /(n+2)$ which is strictly increasing in $n$.

Let's take any power function distribution $F(\theta)=\theta^{a}$ :

$$
\frac{E\left[Y_{2}^{2}\right]}{E\left[Y_{1}\right]}=\frac{a(n-1)(1+a n)}{(2+a(n-1))(2+a n)}
$$

Taking the first derivative with respect to $n$ and simplifying gives:

$$
\frac{d S}{d n}=\frac{2(a-1)}{(2+a(n-1))^{2}}+\frac{2+a}{(2+a n)^{2}}
$$


The expression above is clearly positive for $a \geq 1$. For $a<1$

$$
\frac{2+a}{(2+a n)^{2}}>\frac{2(1-a)}{(2+a(n-1))^{2}}
$$

After few algebraic steps we get

$$
a^{3}\left((n-1)^{2}+n^{2}\right)+2 a^{2}(2 n-1)>0
$$

which always holds for any $n \geq 2$. 


\section{Proof of Proposition 5}

Let's define the expected value of the LHS of equation $(12)$ as

$$
R=\int_{0}^{1}\left(\theta_{i}-2 \frac{1-F\left(\theta_{i}\right)}{f\left(\theta_{i}\right)}\right) f_{1}\left(\theta_{i}\right) d \theta_{i}
$$

where $f_{1}($.$) is the density function of the first order statistic of n$ independently drawn $\theta$. To prove that the expected agent's ideological compromise is lower under the optimal mechanism with ex-ante fixed mission than under the optimal scoring auction, I need to show that $R(\theta)<$ $E\left[Y_{2}^{2}\right] / E\left[Y_{1}\right]$. Let's start by rewriting

$$
R=E\left[Y_{1}\right]-2 n\left(E\left[Y_{1}\right]-E\left[Y_{1}^{(n-1)}\right]\right)
$$

where $E\left[Y_{1}^{(n-1)}\right]$ is the expected value of the first order statistics of $(n-1)$ independent drawn values of $\theta$. Notice that

$$
2 n E\left[Y_{1}^{(n-1)}\right]=2\left(E\left[Y_{2}\right]+(n-1) E\left[Y_{1}\right]\right)
$$

which, after few algebraic steps, gives

$$
R=2 E\left[Y_{2}\right]-E\left[Y_{1}\right]
$$

Thus, it is sufficient to show that

$$
2 E\left[Y_{2}\right]-E\left[Y_{1}\right]<\frac{E\left[Y_{2}^{2}\right]}{E\left[Y_{1}\right]}
$$

which then leads to

$$
-\left(E\left[Y_{1}\right]-E\left[Y_{2}\right]\right)^{2}<E\left[Y_{2}^{2}\right]-E\left[Y_{2}\right]^{2}
$$

The equation above always holds as the LHS is negative and the RHS is positive. Since

$$
\frac{\left(1-F_{2}(\underline{\theta})\right) E\left(Y_{2}^{2} \mid Y_{2}>\underline{\theta}\right)+\underline{\theta}^{2} F(\underline{\theta})^{n-1}(1-F(\underline{\theta})) n}{\left(1-F_{1}(\underline{\theta})\right) E\left(Y_{1} \mid Y_{1}>\underline{\theta}\right)} \geq \frac{E\left[Y_{2}^{2}\right]}{E\left[Y_{1}\right]}
$$

I have shown that under the optimal price-only competition (with or without exclusion), the agent's expected ideological compromise is lower than under the optimal scoring auction. 


\section{Proof of Proposition 6}

I restrict my attention to contracts in which $m(\theta)$ is continuous. This implies that for the contracts to be incentive compatible $p(\theta)$ must also be continuous ${ }^{25}$ The overall proof is made up of several Lemmas.

Lemma 1 Under a direct and truthful mechanism, there cannot be more than one type that exerts his optimal-unconstrained- level of effort and for which the budget constraint binds, i.e. $p(\theta)=\frac{1}{2} \theta^{2} G\left(m_{A}-m(\theta)\right)^{2}$.

PROOF[by contradiction]: Consider type $(\theta-\epsilon)$ and type $\theta$, for which the budget constraints are binding, namely $p(\theta)=\frac{1}{2} \theta^{2} G\left(m_{A}-m(\theta)\right)^{2}$ and $p(\theta-\epsilon)=\frac{1}{2}(\theta-\epsilon)^{2} G\left(m_{A}-m(\theta-\epsilon)\right)^{2}$. Notice that type $\theta$ would be budget constrained under the contract of type $(\theta-\epsilon)$, whereas the latter would exert his optimal level of effort under the contract of type $\theta$. Under a direct and truthful mechanism the following two conditions must hold:

$$
\begin{gathered}
\theta^{2} G\left(m_{A}-m(\theta)\right)^{2} \geq \theta(\theta-\epsilon) G\left(m_{A}-m(\theta-\epsilon)\right)^{2} \\
(\theta-\epsilon)^{2} G\left(m_{A}-m(\theta-\epsilon)\right)^{2} \geq \frac{1}{2}\left(\theta^{2}+(\theta-\epsilon)^{2}\right) G\left(m_{A}-m(\theta)\right)^{2}
\end{gathered}
$$

where (A-9) refers to the incentive compatibility constraint for type $\theta$ (agent $\theta$ gets higher utility by reporting his true type than by reporting type $(\theta-\epsilon))$ and $\mathrm{A}-10 \mathrm{l}$ refers to the incentive compatibility constraint for type $(\theta-\epsilon)$ (agent $(\theta-\epsilon)$ gets higher utility by reporting his true type than by reporting type $\theta$ ). Rearranging (A-9) and (A-10) gives respectively:

$$
\begin{gathered}
\frac{\theta}{\theta-\epsilon} \geq \frac{G\left(m_{A}-m(\theta-\epsilon)\right)^{2}}{G\left(m_{A}-m(\theta)\right)^{2}} \\
\frac{G\left(m_{A}-m(\theta-\epsilon)\right)^{2}}{G\left(m_{A}-m(\theta)\right)^{2}} \geq \frac{\theta^{2}+(\theta-\epsilon)^{2}}{2(\theta-\epsilon)^{2}}
\end{gathered}
$$

These two conditions cannot be simultaneously satisfied since $\frac{\theta^{2}+(\theta-\epsilon)^{2}}{2(\theta-\epsilon)^{2}}>\frac{\theta}{\theta-\epsilon}$ :

$$
\begin{gathered}
\Leftrightarrow \frac{\theta^{2}+(\theta-\epsilon)^{2}}{2(\theta-\epsilon)}>\theta \\
\Leftrightarrow \theta^{2}+(\theta-\epsilon)^{2}>2 \theta(\theta-\epsilon) \\
\Leftrightarrow(\theta-(\theta-\epsilon))^{2}>0 \\
\Leftrightarrow \epsilon^{2}>0
\end{gathered}
$$

which is true for any $\epsilon \neq 0$. This proves Lemma 1 .

\footnotetext{
${ }^{25}$ Suppose that the optimal mechanism involves a downward (upward) jump in $p($.$) at the point \theta=\tilde{\theta}$ while $m($.$) is continuous in that point. Then, the contract (m(\tilde{\theta}+\epsilon), p(\tilde{\theta}+\epsilon))$ with $\epsilon \rightarrow 0$ is less (more) attractive than the contract $(m(\tilde{\theta}-\epsilon), p(\tilde{\theta}-\epsilon))$ for all types, which implies that the incentive compatibility constraint is violated.
} 
Corollary 1 There can be only one interval in which the agent is budget constrained under a direct and truthful mechanism, and this interval must include the highest type, $\theta=1$.

PROOF: By the continuity assumption on $m(\theta), p(\theta)$ and $g(m(\theta), \theta)=\frac{1}{2} \theta^{2} G\left(m_{A}-m(\theta)\right)^{2}$ must also be continuous in $\theta$. Therefore, if agents of type $\theta \in[\underline{\theta}, \bar{\theta}] \subset(0,1)$ are budget constrained under a direct and truthful mechanism, then it must be true that $p(\underline{\theta})=g(m, \underline{\theta})$ and that $p(\bar{\theta})=g(m, \bar{\theta})$. However, Lemma 1 shows that under any implementable mechanism there can't be more than one type that exerts his optimal -unconstrained- level of effort and for which the budget constraint is binding. Therefore under the direct and truthful mechanism there can't be an interval $[\underline{\theta}, \bar{\theta}] \subset(0,1)$ such that all types in that interval are budget constrained. Finally, notice that type $\theta=0$ cannot be budget constrained since his optimal level of effort is equal to zero. Corollary 1 then follows: under a direct and truthful mechanism the only interval of types for which the budget constraints can be binding is of the form: $[\bar{\theta}, 1]$. It also implies that $p(\bar{\theta})=\frac{1}{2} \bar{\theta}^{2} G\left(m_{A}-m(\bar{\theta})\right)^{2}$.

So we are left with three possible cases: $\bar{\theta}=1$, i.e. no agent is budget constrained; $\bar{\theta} \rightarrow 0$, i.e. all agents are budget constrained; and $\bar{\theta} \in(0,1)$, i.e. types in $[0, \bar{\theta}]$ exert their optimal -unconstrained- level of effort, while types in $[\bar{\theta}, 1]$ are budget constrained. I will now analyze each of these cases separately.

\section{Case 1: $\bar{\theta}=1$}

We are in the case in which all types in the interval $[0,1]$ exert their optimal -unconstrainedlevel of effort. Together with Lemma 1, this implies that the budget constraint is binding for the highest type, i.e. $p(1)=\frac{1}{2} G\left(m_{A}-m(1)\right)^{2}$, and is slack for all remaining types, i.e. $p(\theta)>\frac{1}{2} \theta^{2} G\left(m_{A}-m(\theta)\right)^{2} \forall \theta \in[0,1)$.

Lemma 2 If all types in the interval $[0,1]$ exert their optimal-unconstrained-level of effort under a direct and truthful mechanism, then $m(\theta)$ must be non-decreasing in that interval.

To prove Lemma 2 I first need the following step:

Step 1 The agent always exerts his optimal-unconstrained- level of effort under deviation $\Longleftrightarrow$ $m(\theta)$ is non-decreasing.

PROOF: If the agent is never budget constrained under deviation, he exerts effort $e=$ $\theta_{i} G\left(m_{A}-m(z)\right)$ for all $z$, the latter being the reported type. Thus, the incentive compatibility constraint can be written as follows: 


$$
U(\theta)=\max _{z \in \Theta}\left\{p(z)+\frac{1}{2} \theta^{2} G\left(m_{A}-m(z)\right)^{2}\right\}
$$

Remind that we defined $g(m, \theta)=\frac{1}{2} \theta^{2} G\left(m_{A}-m\right)^{2}$. Then:

$$
\frac{\partial g(m, \theta)}{\partial m \partial \theta}=2 \theta G\left(m_{A}-m\right) G^{\prime}\left(m_{A}-m\right)(-1)>0
$$

which implies that $g(m, \theta)$ has strict single crossing differences in $(m, \theta)$. By the Monotonic Selection Theorem we then know that $m(\theta)$ must be non-decreasing. This proves the right direction of the relationship in Step 1. Now suppose that under the direct and truthful mechanism $m(\theta)$ is increasing in the interval $[0,1]$. For the incentive compatibility constraint to be satisfied, $p(\theta)$ must be decreasing in that interval since the agent's utility is increasing in both $m(\theta)$ and $p(\theta)$. Now, if agent $\theta$ deviates downwards, he gets a lower level of discretion and a higher payment, so if he is not budget constrained by reporting his true type, he won't be budget constrained by reporting a lower type. If agent $\theta$ deviates upwards, he gets more discretion and a lower payment. However, since by assumption type $(\theta+\epsilon)$ is not budget constrained by reporting his true type, neither will be type $\theta$ by reporting $(\theta+\epsilon)$. This proves the left direction of the relationship in Step 1.

With step 1 in mind, I can now proceed with proof of Lemma 2:

PROOF[by contradiction]: Suppose that under the direct and truthful mechanism $m(\theta)$ is decreasing in $[0,1]$. Then, it is always possible to construct an interval $[\theta-\epsilon, \theta+\epsilon] \subset[0,1]$ in which the agent would exert his optimal - unconstrained- level effort under deviations in that interval. If $m(\theta)$ is decreasing, by reporting type $z=(\theta+\epsilon)$ rather than his true type, agent $\theta$ would get a higher payment and less discretion, so he would not be budget constrained. As far as deviations downwards are concerned, let's first remind that by Lemma 1 the budget constraints must be slack for all types $[0,1)$. Therefore, by the continuity assumption above, there must always exist an $\epsilon$ small enough such that

$$
p(\theta)>p(\theta-\epsilon) \geq \frac{1}{2} \theta^{2} G\left(m_{A}-m(\theta-\epsilon)\right)^{2}>\frac{1}{2} \theta^{2} G\left(m_{A}-m(\theta)\right)^{2}
$$

which means that under the contract for type $(\theta-\epsilon)$, agent $\theta$ exerts his optimal level of effort. From step 1 we know that $m(\theta)$ must be non-decreasing in the interval $[\theta-\epsilon, \theta+\epsilon]$, which contradicts the initial assumption of $m(\theta)$ being decreasing in [0,1]. This proves Lemma 2 .

Lemma 3 There is always a pooling contract that gives the principal a higher utility than a (full or partial) separating contract under which all types exert their optimal - unconstrainedlevel of effort. 
PROOF: Suppose there is a contract $\left(m^{s}(\theta), p^{s}(\theta)\right)$ that (fully or partially) separates on the entire interval of types, $[0,1]$, and under which any agent is exerting his optimal - unconstrainedlevel of effort. From Lemma 2 we know that for such contract to be implementable, $m^{s}(\theta)$ must be non-decreasing in $[0,1]$, which in turn implies that $p^{s}(\theta)$ must be non-increasing. Therefore, the following inequalities must hold:

$$
\begin{gathered}
m^{s}(1) \geq m^{s}(\theta) \forall \theta \\
p^{s}(\theta) \geq p^{s}(1)=\frac{1}{2} G\left(m_{A}-m^{s}(1)\right)^{2} \forall \theta
\end{gathered}
$$

I will now show that the principal gets a higher utility by offering the following pooling contract to all types :

$$
\begin{gathered}
m^{p}=\min \left\{m^{s}(1), \tilde{m}\right\} \\
p^{p}=\min \left\{\frac{1}{2} G\left(m_{A}-m^{s}(1)\right)^{2}, \frac{1}{2} G\left(m_{A}-\tilde{m}\right)^{2}\right\}
\end{gathered}
$$

where $\tilde{m}=\arg \max _{m} Y(\theta, m)=\theta \theta_{D} G\left(m-m_{D}\right) G\left(m_{A}-m\right)$. In other words, $\tilde{m}$ is the mission that maximizes the utility that the principal gets from the project's output if the agent exerts his optimal -unconstrained- level of effort. Notice that $\tilde{m}$ does not depend on $\theta$. Recall that the principal's expected utility from allocating the contract to an agent of type $\theta$ is $E\left(V_{D}\right)=\int_{0}^{1}(Y(\theta, m)-p(\theta)) f(\theta) d \theta$.

Suppose $m^{s}(1)<\tilde{m}$. This means that, everything else being equal, the principal could increase his utility by increasing the level of discretion of all agents. More specifically, by offering a contract with mission $m^{p}=m^{s}(1)$ and payment $p^{p}=\frac{1}{2} G\left(m_{A}-m^{s}(1)\right)^{2}$ to all types, the latter would still exert their optimal - unconstrained - level of effort, so the principal would not only increase $Y(\theta, m)$ for all types but, by $(\mathrm{A}-12)$, he would also decrease $p(\theta)$ for all types. Therefore, under that pooling contract principal's utility will be unambiguously higher than under any implementable (full or partial) separating contract $\left(m^{s}(\theta), p^{s}(\theta)\right)$.

Suppose now that $m^{s}(1)>\tilde{m}$. Then, everything else being equal, the principal could increase his utility by increasing the level of discretion of those types for which $m^{s}(\theta)<\tilde{m}$ and by decreasing the level of discretion of those types for which $m^{s}(\theta)>\tilde{m}$. More specifically, by offering a contract with mission $m^{p}=\tilde{m}$ and payment $p^{p}=\frac{1}{2} G\left(m_{A}-\tilde{m}\right)^{2}$ to all types, the latter would still exert their optimal -unconstrained- level of effort, so the principal would not only increase $Y(\theta, m)$ for all types, but by equation $\mathrm{A}-12$ and the fact that $m^{s}(1)>\tilde{m}$, he would also decrease $p(\theta)$ for all types. Therefore, under that pooling contract principal's utility will be unambiguously higher than under any implementable (full or partial) separating contract $\left(m^{s}(\theta), p^{s}(\theta)\right)$. This proves Lemma 3. We now turn to the case in which all types are budget constrained. 
Case 2: $\bar{\theta} \rightarrow 0$

The maximization problem faced by the principal when all types are budget constrained is

$$
\begin{array}{r}
\max _{m, p} V_{D}=\theta_{D} G\left(m(\theta)-m_{D}\right) \sqrt{2 p(\theta)}-p(\theta) \\
\text { s.t. } p(\theta)<\frac{1}{2} G\left(m_{A}-m(\theta)\right)^{2} \forall \theta
\end{array}
$$

Note that it does not depend directly on $\theta$. The solution to the unconstrained problem is to offer the pooling contract $\left(m_{D}, p=\frac{1}{2} \theta_{D}^{2} G(0)^{2}\right)$ to all types. However, for this solution to be feasible it must satisfy the inequality constraints $p(\theta)<\frac{1}{2} G\left(m_{A}-m(\theta)\right)^{2} \forall \theta$. In other words, it must be true that

$$
e=\min \left\{\theta G\left(m_{A}-m_{D}\right), \theta_{D} G(0)\right\}=\theta_{D} G(0) \quad \forall \theta \in[0,1]
$$

This condition never holds for any $\theta<\theta_{D}$. Therefore, under the optimal mechanism there must be some types who exert their optimal -unconstrained- level of effort. We now look at that last case.

\section{Case 3: $\bar{\theta} \in(0,1)$}

Suppose types in the interval $[0, \bar{\theta}]$ exert their optimal -unconstrained- level of effort, while types in the interval $[\bar{\theta}, 1]$ are budget constrained. The budget constraint binds for type $\bar{\theta}$, i.e. $p(\bar{\theta})=\frac{1}{2} \bar{\theta}^{2} G\left(m_{A}-m(\bar{\theta})\right)^{2}$. This part of the proof is divided in two Lemmas. In the first Lemma I prove that there exists no incentive compatible mechanism with decreasing $m(\theta)$, in the second Lemma I prove that there always exists a pooling contract that outperforms a separating mechanism with increasing $m(\theta)$.

Lemma 4 There exists no implementable mechanism in which $m(\theta)$ is (partly or fully) decreasing in the interval of types who are budget constrained.

PROOF: From Lemma 2 we know that under any direct and truthful mechanism $m(\theta)$ must be non-decreasing in the interval $[0, \bar{\theta}]$. Now suppose that $m(\theta)$ is partly or fully decreasing in the interval $[\bar{\theta}, 1]$. This implies that $m(\theta)$ must be -strictly-increasing in the interval $[0, \bar{\theta}]$. Indeed, notice that $p(\theta)$ must reach a global maximum at $\theta=0$ - and therefore $m(\theta)$ must reach a global minimum at $\theta=0$ - otherwise type 0 who does not care about any mission would deviate to the contract with the highest payment. 
Now suppose that $m(\theta)$ is increasing in the interval $[\bar{\theta}, \hat{\theta}]$ and decreasing in the interval $[\hat{\theta}, \check{\theta}]$, with $\bar{\theta}<\hat{\theta}<\check{\theta} \leq 1$. It follows that the function $m(\theta)$ reaches a local maximum at $\theta=\hat{\theta}$. Thus, some types below $\hat{\theta}$ must receive the same contract as some types above $\hat{\theta}$. Suppose type $(\hat{\theta}-\epsilon)$ receives the same contract, $(\tilde{m}, \tilde{p})$, as type $(\hat{\theta}+y)$, where $\epsilon, y>0$, and $(\hat{\theta}-\epsilon)>\bar{\theta}$. On the other hand, type $\hat{\theta}$ receives the contract $(\hat{m}, \hat{p})$. The utility of agent $\hat{\theta}$ when reporting is truth type is

$$
U(\hat{\theta}, \hat{\theta})=\hat{\theta} G\left(m_{A}-\hat{m}\right) \sqrt{2 \hat{p}}
$$

Whereas his utility when reporting type $(\hat{\theta}-\epsilon)$ is

$$
U(\hat{\theta}, \hat{\theta}-\epsilon)=\hat{\theta} G\left(m_{A}-\tilde{m}\right) \sqrt{2 \tilde{p}}
$$

Indeed, if type $(\hat{\theta}-\epsilon)$ is budget constrained under contract $(\tilde{m}, \tilde{p})$, so will be type $\hat{\theta}$. For the incentive compatibility constraint to hold, it must be true that $U(\hat{\theta}, \hat{\theta}) \geq U(\hat{\theta}, \hat{\theta}-\epsilon)$, i.e. $G\left(m_{A}-\hat{m}\right) \sqrt{2 \hat{p}} \geq G\left(m_{A}-\tilde{m}\right) \sqrt{2 \tilde{p}}$. Similarly, the utility of agent $(\hat{\theta}+y)$ when revealing his true type is

$$
U(\hat{\theta}+y, \hat{\theta}+y)=(\hat{\theta}+y) G\left(m_{A}-\tilde{m}\right) \sqrt{2 \tilde{p}}
$$

Whereas his utility when reporting type $\hat{\theta}$ is

$$
U(\hat{\theta}+y, \hat{\theta})=(\hat{\theta}+y) G\left(m_{A}-\hat{m}\right) \sqrt{2 \hat{p}}
$$

Under a direct and incentive compatible mechanism it must hold that $U(\hat{\theta}+y, \hat{\theta}+y) \geq U(\hat{\theta}+$ $y, \hat{\theta})$, i.e. $G\left(m_{A}-\tilde{m}\right) \sqrt{2 \tilde{p}} \geq G\left(m_{A}-\hat{m}\right) \sqrt{2 \hat{p}}$. This is a contradiction with what I found above. The incentive compatibility constraints of type $\hat{\theta}$ and of type $\hat{\theta}+y$ cannot be simultaneously satisfied unless contract $(\tilde{m}, \tilde{p})$ is equal to contract $(\hat{m}, \hat{p})$. This is true for any $\hat{\theta}-\epsilon>\bar{\theta}$, any $\hat{\theta}+y$, and any $\check{\theta}$.

I am now left to check what happens when $m(\theta)$ starts decreasing at $\theta=\bar{\theta}$. This implies that $m(\theta)$ reaches a local maximum at $\theta=\bar{\theta}$. It follows that each type in the interval $[\bar{\theta}, 1]$ is offered the same contract as a lower type $\theta<\bar{\theta}$ who is not budget constrained. Indeed if this was not the case, there would be contracts with same missions but different payments, so this mechanism would not be incentive compatible. It follows that each contract offered to types that are budget constrained, namely to $\theta \in[\bar{\theta}, 1]$, must also satisfy the incentive compatibility constraint of a type that exerts his optimal - unconstrained- level of effort, $\theta \in[0, \bar{\theta}]$. I will now show that this is not possible. More specifically, I will show that under such mechanism, types $(\bar{\theta}, 1]$ have an incentive to deviate to the contract of type $\bar{\theta}$. 
Suppose, for instance, that type $(\bar{\theta}+\epsilon)$ with $\epsilon>0$ is offered the same contract as type $\hat{\theta} \in[0, \bar{\theta})$, which we define as $(\hat{m}, \hat{p})$. As stated above, this contract must satisfy the incentive compatibility constraint of type $\hat{\theta}$. Since $m^{s}(\theta)$ is increasing in $[0, \bar{\theta}]$, agent $\hat{\theta}$ exerts his optimal -unconstrained- level of effort under his contract and, by Step 1, also under any deviation in $[0, \bar{\theta}]$. More generally, I can write the incentive compatibility constraint of type $\theta \in[0, \bar{\theta}]$ as follows:

$$
U(\theta)=\max _{z \in[0, \bar{\theta}]}\left\{p(z)+\frac{1}{2} \theta^{2} G\left(m_{A}-m(z)\right)^{2}\right\}
$$

Applying the envelope theorem, the next steps are standard:

$$
\begin{gathered}
U^{\prime}(\theta)=\theta G\left(m_{A}-m(\theta)\right)^{2} \\
U(\theta)=U(0)+\int_{0}^{\theta} t G\left(m_{A}-m(t)\right)^{2} d t
\end{gathered}
$$

From there we can easily pin down $\hat{p}$ as a function of $\hat{m}$ :

$$
\hat{p}=p(\hat{m})=p(0)-\frac{1}{2} \hat{\theta}^{2} G\left(m_{A}-\hat{m}\right)^{2}+\int_{0}^{\hat{\theta}} t G\left(m_{A}-m(t)\right)^{2} d t
$$

where $\hat{\theta}=m^{-1}(\hat{m})$, so $\hat{\theta}$ is a function of $\hat{m}$. Therefore, we can write down the utility of type $(\bar{\theta}+\epsilon)$ when he reports his type truthfully, as a function of $\hat{m}$ :

$$
U(\bar{\theta}+\epsilon, \hat{m})=(\bar{\theta}+\epsilon) G\left(m_{A}-\hat{m}\right) \sqrt{2 p(\hat{m})}
$$

Now, it is important to notice that if type $(\bar{\theta}+\epsilon)$ does not report his type truthfully but deviates downwards, he will still remain budget constrained. Indeed, if type $(\bar{\theta}+\epsilon-y)$, with $\epsilon-y \geq 0$, is budget constrained under his own contract $(\check{m}, \check{p}){ }^{26}$, so will be type $(\bar{\theta}+\epsilon)$ under that same contract. This means that the utility of type $(\bar{\theta}+\epsilon)$ by reporting type $(\bar{\theta}+\epsilon-y)$ will be

$$
U(\bar{\theta}+\epsilon, \check{m})=(\bar{\theta}+\epsilon) G\left(m_{A}-\check{m}\right) \sqrt{2 p(\check{m})}
$$

A sufficient condition for this mechanism not to be incentive compatible is $U(\bar{\theta}+\epsilon, \check{m})>$ $U(\bar{\theta}+\epsilon, \hat{m})$ for all $\epsilon>0$. Since $\check{m}>\hat{m}$, this is true if and only if $U(\bar{\theta}+\epsilon, \hat{m})$ is strictly increasing in $\hat{m}$ for all $\epsilon$. I will now show that this is indeed the case.

Let's first calculate:

$$
\frac{d p(\hat{m})}{d \hat{m}}=\frac{\partial p}{\partial \hat{\theta}} \hat{\theta}^{\prime}(\hat{m})+\frac{\partial p}{\partial \hat{m}}
$$

\footnotetext{
${ }^{26}$ It is important to remind that all types in the interval $(\bar{\theta}, 1]$ receive the same contract as a lower type in the interval $[0, \bar{\theta})$. Therefore, also the contract $(\check{m}, \check{p})$ must satisfy equation A-15
} 
Notice that $\frac{\partial p}{\partial \hat{\theta}}=0$, so the expression above simplifies to

$$
\frac{d p(\hat{m})}{d \hat{m}}=-\hat{\theta}^{2} G\left(m_{A}-\hat{m}\right) G^{\prime}\left(m_{A}-\hat{m}\right)(-1)
$$

Using the product rule we then get:

$\frac{\partial U(\bar{\theta}+\epsilon, \hat{m})}{\partial \hat{m}}=(\bar{\theta}+\epsilon)\left(G^{\prime}\left(m_{A}-\hat{m}\right)(-1) \sqrt{2 \hat{p}}-\frac{G\left(m_{A}-\hat{m}\right)}{\sqrt{2 \hat{p}}} \hat{\theta}^{2} G\left(m_{A}-\hat{m}\right) G^{\prime}\left(m_{A}-\hat{m}\right)(-1)\right)$

Rearranging the expression above we get:

$$
\frac{\partial U(\bar{\theta}+\epsilon, \hat{m})}{\partial \hat{m}}=(\bar{\theta}+\epsilon)\left(G^{\prime}\left(m_{A}-\hat{m}\right)(-1)\left(\sqrt{2 \hat{p}}-\frac{\hat{\theta}^{2} G\left(m_{A}-\hat{m}\right)^{2}}{\sqrt{2 \hat{p}}}\right)\right)
$$

whose sign depends on the term $\left(\sqrt{2 \hat{p}}-\frac{\hat{\theta}^{2} G\left(m_{A}-\hat{m}\right)^{2}}{\sqrt{2 \hat{p}}}\right)$. Since $\hat{\theta} \in[0, \bar{\theta})$ then it must be true that $\sqrt{2 \hat{p}}>\hat{\theta} G\left(m_{A}-\hat{m}\right)$. This implies that the sign of $\left(\sqrt{2 \hat{p}}-\frac{\hat{\theta}^{2} G\left(m_{A}-\hat{m}\right)^{2}}{\sqrt{2 \hat{p}}}\right)$ is positive, and so is the sign of A-19). This holds for any pairs $\hat{\theta}$ and $\epsilon>0$. So we conclude that types $\theta \in(\bar{\theta}, 1]$ want to deviate to the contract with the highest $m$, that is, to the contract of type $\bar{\theta}$. Therefore, a mechanism with decreasing $m(\theta)$ in the interval $[\bar{\theta}, 1]$ is never incentive compatible. This proves Lemma 4.

I now look at the case with increasing $m(\theta)$.

Lemma 5 There is always a pooling contract that gives the principal a higher utility than any (partial or full) separating contract with non-decreasing $m(\theta)$ and binding budget constraints for types $[\bar{\theta}, 1]$.

To prove Lemma 5 we first need the following step:

Step 2 Under the optimal mechanism, the utility that the principal gets from contracting with the highest type must be at least as large as the utility he gets from contracting with any lower type, i.e. $V_{D}(1, m(1), p(1)) \geq V_{D}(\theta, m(\theta), p(\theta)) \forall \theta<1$.

PROOF[by contradiction]: Suppose that under the optimal mechanism agent $\hat{\theta}$ receives the contract $(m(\hat{\theta}), p(\hat{\theta}))$, which gives the principal an utility equal to $V_{D}(\hat{\theta}, m(\hat{\theta}), p(\hat{\theta}))$. It is then straightforward to verify that by offering this same contract to a higher type, the principal gets at least this same level of utility, namely $V_{D}(\theta, m(\hat{\theta}), p(\hat{\theta})) \geq V_{D}(\hat{\theta}, m(\hat{\theta}), p(\hat{\theta})) \forall \theta>\hat{\theta}$. It follows that the principal can always improve upon a mechanism in which his utility is highest at $\theta=\hat{\theta}$ by offering the same contract offered to $\hat{\theta}$ to all $\theta \in(\hat{\theta}, 1]$. This holds for any $\hat{\theta}<1$. 
Therefore under the optimal mechanism, the contact offered to type 1 must generate to the principal at least the same level of utility as any other contract offered to a lower type.

With step 2 in mind, we now proceed with proving Lemma 5.

PROOF: Suppose there is an original contract $\left(m^{s}(\theta), p^{s}(\theta)\right)$ that separates over the full interval of types and that the budget constraints bind in the interval $[\bar{\theta}, 1]$. From Lemma 2 we know that under any incentive compatible separating mechanism, $m^{s}($.$) must be increasing in$ the interval $[0, \bar{\theta}]$. So now suppose that $m^{s}($.$) is also increasing in the interval [\bar{\theta}, 1]$, such that $m^{s}($.$) is increasing and p^{s}($.$) is decreasing in the entire interval of types. From Step 2$ we know that since the contract is separating on the interval $[\bar{\theta}, 1]$ :

$$
V_{D}^{f c}\left(m^{s}(1), p^{s}(1)\right) \geq V_{D}^{f c}\left(m^{s}(\theta), p^{s}(\theta)\right) \forall \theta \in[\bar{\theta}, 1)
$$

where $V_{D}^{f c}\left(m^{s}(\theta), p^{s}(\theta)\right)$ is the utility that the principal gets from agent $\theta$ when the latter is budget constrained under his contract. Similarly, we define by $V_{D}^{n f c}\left(\theta, m^{s}(\theta), p^{s}(\theta)\right)$ the utility that the principal gets from agent $\theta$ when the latter exerts his optimal -unconstrained - level of effort under his contract. There can be three scenarios: $\tilde{m}>m^{s}(1)>m^{s}(\bar{\theta})$, $m^{s}(1)>m^{s}(\bar{\theta})>\tilde{m}$, and $m^{s}(1)>\tilde{m}>m^{s}(\bar{\theta})$, where $\tilde{m}$ is defined as before, namely $\tilde{m}=$ $\arg \max _{m} Y(\theta, m)=\theta \theta_{D} G\left(m-m_{D}\right) G\left(m_{A}-m\right)$.

Suppose $\tilde{m}>m^{s}(1)>m^{s}(\bar{\theta})$. I will now show that the principal is better off by offering the pooling contract $\left(m^{s}(1), p^{s}(1)\right)$ to all types. Assume he does so. Under the contract $\left(m^{s}(1), p^{s}(1)\right)$, types in the interval $[\bar{\theta}, 1]$ are still budget constrained since they get more discretion and a lower payment than in the original contract. Therefore, they generate utility for the principal equal to $V_{D}^{f c}\left(m^{s}(1), p^{s}(1)\right)$. From step 2, we then know that principal's utility from these types has increased with respect to the original contract. Let's now look at the interval $[0, \bar{\theta}]$. Let's define by $\hat{\theta}$ the lowest type for which the budget constraint binds under the contract $\left(m^{s}(1), p^{s}(1)\right)$. Then, types $[0, \hat{\theta}]$ exert their optimal level of effort as under the original contract. From Lemma 3 we know that principal's utility has increased with respect to the original contract for types in that interval. Finally, let's look at the interval $[\hat{\theta}, \bar{\theta}]$. These types are budget constrained under the contract $\left(m^{s}(1), p^{s}(1)\right)$. Therefore, they generate utility for the principal equal to $V_{D}^{f c}\left(m^{s}(1), p^{s}(1)\right)$. From Step 2, we then know that principal's utility from these types has increased with respect to any original contract. This proves that the principal is better off by offering the pooling contract $\left(m^{s}(1), p^{s}(1)\right)$ than the original separating contract. 
Suppose now that $m^{s}(1)>m^{s}(\bar{\theta})>\tilde{m}$. I will show that in this case the principal is better off by offering the pooling contract $\left(\tilde{m}, p^{s}(1)\right)$ to all types. Let's define by $\hat{\theta}$ the lowest type that is budget constrained under that contract. Assume $\hat{\theta}>\bar{\theta}$. Then, for all $\theta \in[\hat{\theta}, 1]$, the pooling contract $\left(\tilde{m}, p^{s}(1)\right)$ yields a higher utility to the principal than the original separating contract, $\tilde{m}$ being lower than $m^{s}(1)$ :

$$
V_{D}^{f c}\left(\tilde{m}, p^{s}(1)\right)=\theta_{D} G\left(\tilde{m}-m_{D}\right) \sqrt{2 p^{s}(1)}-p^{s}(1)>V_{D}^{f c}\left(m^{s}(1), p^{s}(1)\right)
$$

For all $\theta \in[0, \bar{\theta}]$, who exert their optimal level of effort under both contracts, the pooling contract also yields a higher utility to the principal as $\tilde{m}$ maximizes $Y(\theta, m)$ and $p^{s}(1)<p^{s}(\theta)$ $\forall \theta$. Finally, let's consider types in the the interval $[\bar{\theta}, \hat{\theta}]$. For these types the budget constraints were binding under the original contract but not under the pooling contract. Thus, under the original contract principal's utility from contracting with these types is equal to:

$$
V_{D}^{f c}\left(m^{s}(\theta), p^{s}(\theta)\right)=\theta_{D} G\left(m^{s}(\theta)-m_{D}\right) \sqrt{2 p^{s}(\theta)}-p^{s}(\theta)
$$

Since $\sqrt{2 p^{s}(\theta)}<\theta G\left(m_{A}-m^{s}(\theta)\right)$, notice that:

$$
V_{D}^{n f c}\left(\theta, m^{s}(\theta), p^{s}(\theta)\right)=\theta_{D} \theta G\left(m^{s}(\theta)-m_{D}\right) G\left(m_{A}-m^{s}(\theta)\right)-p^{s}(\theta) \geq V_{D}^{f c}\left(m^{s}(\theta), p^{s}(\theta)\right)
$$

Under the pooling contract principal 's utility from contracting with these types is equal to:

$$
V_{D}^{n f c}\left(\theta, \tilde{m}, p^{s}(1)\right)=\theta_{D} \theta G\left(\tilde{m}-m_{D}\right) G\left(m_{A}-\tilde{m}\right)-p^{s}(1)
$$

which, since $\tilde{m}$ maximizes $Y(\theta, m)$ and $p^{s}(1)<p^{s}(\theta) \forall \theta$, leads us to the following inequality:

$$
V_{D}^{n f c}\left(\theta, \tilde{m}, p^{s}(1)\right)>V_{D}^{n f c}\left(\theta, m^{s}(\theta), p^{s}(\theta)\right) \geq V_{D}^{f c}\left(m^{s}(\theta), p^{s}(\theta)\right)
$$

This proves that the principal is better off by offering the pooling contract $\left(\tilde{m}, p^{s}(1)\right)$.

Now assume $\hat{\theta}<\bar{\theta}$. Using the same arguments as above, we know that principal's utility increases by offering the pooling contract to all types in the intervals $[0, \hat{\theta}]$ and $[\bar{\theta}, 1]$, since these types are either budget constrained or not under both contracts. It is left to check principal's utility for types in the interval $[\hat{\theta}, \bar{\theta}]$. These types are budget constrained under the pooling contract $\left(\tilde{m}, p^{s}(1)\right)$ but not under the original contract. In the latter case, principal's utility from contracting with these types is given by $V_{D}^{n f c}\left(\theta, m^{s}(\theta), p^{s}(\theta)\right)$. Notice that by step 2, $V_{D}^{n f c}\left(\theta, m^{s}(\theta), p^{s}(\theta)\right)$ must be smaller than $V_{D}^{f c}\left(m^{s}(1), p^{s}(1)\right) \forall \theta \in[\hat{\theta}, \bar{\theta}]$. Then, the following inequality must hold:

$$
V_{D}^{f c}\left(\tilde{m}, p^{s}(1)\right)>V_{D}^{f c}\left(m^{s}(1), p^{s}(1)\right)>V_{D}^{n f c}\left(\theta, m^{s}(\theta), p^{s}(\theta)\right)
$$

which proves that the principal is better off by offering the pooling contract $\left(\tilde{m}, p^{s}(1)\right)$ also types in the interval $[\hat{\theta}, \bar{\theta}]$ rather than the original separating contract. 
Last, suppose $m^{s}(1)>\tilde{m}>m^{s}(\bar{\theta})$ and that the principal offers the pooling contract $\left(\tilde{m}, p^{s}(1)\right)$ to all types. Let again define by $\hat{\theta}$ the lowest type that is budget constrained under that pooling contract. It is easy to verify that $\hat{\theta}<\bar{\theta}$ and, using the same arguments as above, that the principal is better off than by offering the original separating contract.

Finally, similar arguments apply if the original contract is pooling in the interval in which the agents are budget constrained, i.e. if $m(\theta)=m^{s}(\bar{\theta})$ for all $\theta \in[\bar{\theta}, 1]$. Since agents $[\bar{\theta}, 1]$ are budget constrained, they all generate an utility to the principal that is equal to the utility generated by type $\bar{\theta}$. Similarly, types $[\bar{\theta}, 1]$ are also budget constrained under the pooling contract $\left(m^{p}, p^{p}\right)$ defined in $(\overline{\mathrm{A}-13})$ and $(\widehat{\mathrm{A}-14})$, and therefore they would all generate the same utility to the principal as type $\bar{\theta}$ under that contract. In Lemma 3 we saw that the principal gets a higher utility by offering that pooling contract to all types $[0, \bar{\theta}]$ - so including to type $\bar{\theta}$ - rather than any separating contract. Therefore, he also gets a higher utility by offering that same pooling contract to types $(\bar{\theta}, 1]$. This completes the proof of Lemma 5 .

To summarize, Lemma 3 and 5 show that there always exists a pooling contract that gives the principal a higher utility than any (full or partial) separating contract with increasing $m(\theta)$. Lemma 1 and Lemma 4 show that a (full or partial) separating contract with decreasing $m(\theta)$ is never implementable. This leads to Proposition 6. More specifically, the optimal pooling contract solves:

$$
\max _{m, p} \theta_{D} G\left(m-m_{D}\right)\left[\left(1-F\left(\frac{\sqrt{2 p}}{G\left(m_{A}-m\right)}\right)\right) \sqrt{2 p}+\int_{0}^{\frac{\sqrt{2 p}}{G\left(m_{A}-m\right)}} \theta G\left(m_{A}-m\right) f(\theta) d \theta\right]-p
$$

which leads to the following FOCs:

$$
\begin{aligned}
& G^{\prime}\left(m-m_{D}\right)\left(1-F\left(\frac{\sqrt{2 p}}{G\left(m_{A}-m\right)}\right)\right) \sqrt{2 p}+ \\
& {\left[G^{\prime}\left(m-m_{D}\right) G\left(m_{A}-m\right)-G\left(m-m_{D}\right) G^{\prime}\left(m_{A}-m\right)\right] \int_{0}^{\frac{\sqrt{2 p}}{G\left(m_{A}-m\right)}} \theta G\left(m_{A}-m\right) f(\theta) d \theta=0} \\
& \theta_{D} G\left(m-m_{D}\right)\left(1-F\left(\frac{\sqrt{2 p}}{G\left(m_{A}-m\right)}\right)\right) \frac{1}{\sqrt{2 p}}-1=0
\end{aligned}
$$

Notice that for A-25 to be satisfied, the term $\left(1-F\left(\frac{\sqrt{2 p}}{G\left(m_{A}-m\right)}\right)\right)$, namely the probability of an agent to be budget constrained, must be higher than zero. This implies that under the optimal pooling contract some types are budget constrained. 


\section{References}

Aghion, P. and J. Tirole (1997). Formal and real authority in organizations. Journal of Political Economy 105(1).

Akerlof, G. A. and R. E. Kranton (2005). Identity and the economics of organizations. Journal of Economic Perspectives 19(1), 9-32.

Akerlof, G. A. and R. E. Kranton (2008). Identity, supervision, and work groups. American Economic Review 98(2), 212-17.

Aldashev, G., E. Jaimovich, and T. Verdier (2013). When warm glow burns: Motivational (mis)allocation in the non-profit sector. Working paper.

Aldashev, G. and T. Verdier (2010). Goodwill bazaar: Ngo competition and giving to development. Journal of Development Economics 91(1), 48-63.

Alonso, R. and N. Matouschek (2008). Optimal delegation. The Review of Economic Studies $75(1)$, pp. 259-293.

Armstrong, M. and J. Vickers (2010). A model of delegated project choice. Econometrica 78(1), 213-244.

Ashraf, N., O. Bandiera, and J. Kelsey (2014). No margin, no mission? a field experiment on incentives for pro-social tasks. Journal of Public Economics. Forthcoming.

Asker, J. and E. Cantillon (2010). Procurement when price and quality matter. The RAND Journal of Economics 41(1), pp. 1-34.

Bartling, B., E. Fehr, and K. M. Schmidt (2012). Screening, competition, and job design: Economic origins of good jobs. American Economic Review 102(2), 834-64.

Bartling, B., E. Fehr, and K. M. Schmidt (2013). Discretion, productivity, and work satisfaction. Journal of Institutional and Theoretical Economics 169(1), 4-22.

Benabou, R. and J. Tirole (2003). Intrinsic and extrinsic motivation. The Review of Economic Studies $70(3)$, pp. 489-520.

Benabou, R. and J. Tirole (2006). Incentives and prosocial behavior. American Economic Review 96(5), 1652-1678.

Besley, T. and M. Ghatak (1999). Public-private partnerships for the provision of public goods: Theory and an application to ngos. STICERD Development Economics Discussion Paper Series, DEDPS 17.

Besley, T. and M. Ghatak (2001). Government versus private ownership of public goods. Quarterly Journal of Economics 116(4), 1343-1372. 
Besley, T. and M. Ghatak (2005). Competition and incentives with motivated agents. American Economic Review 95(3), 616-636.

Besley, T. and M. Ghatak (2006). Sorting with motivated agents: implications for school competition and teacher incentives. Journal of the European Economic Association 4(23), 404-414.

Besley, T. and M. Ghatak (2008). Status incentives. American Economic Review 98(2), 206-11.

Carpenter, J. and E. Gong (2013). Motivating agents: How much does the mission matter? IZA Working paper.

Cassar, L. (2014). Mission choice as a substitute for monetary incentives: Experimental evidence. Working paper.

Chau, N. H. and M. Huysentruyt (2006). Nonprofits and public good provision: A contest based on compromises. European Economic Review 50(8), 1909-1935.

Che, Y. (1993). Design competition through multidimensional auctions. RAND Journal of Economics 24 .

Che, Y.-K. and I. Gale (2003). Optimal design of research contests. American Economic Review 93(3), 646-671.

Dasgupta, S. and D. F. Spulber (1989). Managing procurement auctions. Information Economics and Policy 4(1), 5-29.

Delfgaauw, J. and R. Dur (2007). Signaling and screening of workers' motivation. Journal of Economic Behavior \& Organization 62(4), 605-624.

Delfgaauw, J. and R. Dur (2008). Incentives and workers' motivation in the public sector. Economic Journal 118(525), 171-191.

Englmaier, F. and S. Leider (2012). Contractual and organizational structure with reciprocal agents. American Economic Journal: Microeconomics 4(2), 146-83.

Falk, A. and M. Kosfeld (2006). The hidden costs of control. The American Economic Review 96(5), pp. 1611-1630.

Fehr, E., A. Klein, and K. M. Schmidt (2007). Fairness and contract design. Econometrica $75(1), 121-154$.

Francois, P. (2003). Not-for-profit provision of public services. The Economic Journal 113(486), 53-61.

Francois, P. and M. Vlassopoulos (2008). Pro-social motivation and the delivery of social services. CESifo Economic Studies 54(1), 22-54.

Frankel, A. (2014). Aligned delegation. American Economic Review 104(1), 66-83.

Gerhards, L. (2013). How (not) to incentivize motivated agents - an expeirment with employees 
from a non-profit organization. Working paper.

Ghatak, M. and H. Mueller (2011). Thanks for nothing? not-for-profits and motivated agents. Journal of Public Economics 95(1-2), 94-105.

Ghatak, M. and H. Mueller (2013). Not-for-profits, for-profits and competition. Working paper.

Holmstrom, B. (1984). On the theory of delegation. In M. Boyer and R. Kihlstrom (Eds.), Bayesian Models in Economic Theory. Amsterdam: Elsvier.

Huysentruyt, M. (2011). Development aid by contract: Outsourcing and contractor identity. Working paper.

Kosfeld, M. and F. von Siemens (2011). Competition, cooperation, and corporate culture. The RAND Journal of Economics 42(1), pp. 23-43.

Krishna, V. (2002). Auction theory. Academic Press.

Laffont, J.-J. and J. Tirole (1987). Auctioning incentive contracts. Journal of Political Economy 95(5), 921-37.

McAfee, R. P. and J. McMillan (1987). Competition for agency contracts. RAND Journal of Economics 18(2), 296-307.

Murdock, K. (2002). Intrinsic motivation and optimal incentive contracts. The RAND Journal of Economics 33(4), pp. 650-671.

Myerson, R. B. (1981). Optimal auction design. Mathematics of Operations Research 6(1), $58-73$.

Perry, J., A. Hondeghem, and L. Wise (2010). Revisiting the motivational bases of public service: twenty years of research and an agenda of the future. Public Administration Review 70(5), 681-690.

Prendergast, C. (2007). The motivation and bias of bureaucrats. American Economic Review $97(1), 180-196$.

Prendergast, C. (2008). Intrinsic motivation and incentives. American Economic Review 98(2), 201-05. 